\title{
Moving the centre to design social media in rural Africa
}

\author{
Nicola J. Bidwell ${ }^{\star}$
}

\begin{abstract}
Efforts to design voice-based, social media platforms for low-literacy communities in developing countries have not widened access to information in the ways intended. This article links this to who describes the relations that constitute personhood and how these relations are expressed in designing and deploying systems. I make these links oriented by critique in human-computer interaction that design continues a history of colonialism and embeds meanings in media that disrupt existing communication practices. I explore how we translated 'logics' about sociality through logics located outside of the rural South African community that we targeted for design and deployment. The system aimed to enable inhabitants to record, store and share voice files using a portable, communally owned display. I describe how we engaged with inhabitants, to understand needs, and represented and abstracted from encounters to articulate requirements, which we translated into statements about technology. Use of the system was not as predicted. My analysis suggests that certain writing cultures, embedded in translations, reify knowledge, disembody voices and neglect the rhythms of life. This biases social media towards
\end{abstract}

This article is dedicated to Irie, Pebee and Vinca Jampo.

N. J. Bidwell $\left(^{\star}\right)$

Department of Computer Science, University of Namibia, Private Bag 13301, Windhoek, Namibia

e-mail: nic.bidwell@gmail.com; nbidwell@unam.na

N. J. Bidwell

Department of Informatics, University of Pretoria, Pretoria, South Africa

N. J. Bidwell

Digital Ethnography Group, Royal Melbourne Institute of Technology, Melbourne, Australia individualist logics and limits affordances for forms, genres and other elements of communication that contribute to sociality. Thus, I propose oral practices offer oppositional power in designing digital bubbles to support human togetherness and that we can enrich design by moving the centre—a phrase taken from Ngũgĩ wa Thiong'o (Moving the centre: the struggle for cultural freedoms, James Currey, London, 1993) who insists that liberation from colonialism requires plural sites of creativity. To realize this potential, we need radically different approaches that enable symmetrical translation.

Keywords Post-colonial computing - Decolonizing design - Oral practice $\cdot$ Personhood - Voice-based systems $\cdot$ Rural Africa

\section{Introduction}

Efforts to design social media platforms that enable sharing locally relevant information orally amongst technologically sparse communities in developing countries have intensified recently. Some strategies for creating and sharing information use lower-cost channels on cell phone networks to share audio asynchronously in interactive voice forums (IVF) (e.g. Patel et al. 2010; Mudliar et al. 2012). Others involve sharing multimedia via displays in common access sites (e.g. Frohlich et al. 2009; Best et al. 2010). There are few prolonged studies, but analyses of some short-term deployments in rural communities suggest that they did not widen information sharing. Few farmers who participated in an IVF in India conveyed what they learnt to those who could not participate (Patel et al. 2010); only a subset of users authored audio-photograph stories posted to a shared display in rural India (Frohlich et al. 2009); 
and, women were less able than men to take part in an IVF in rural Tanzania (Sullivan 2012).

This article argues that the ability of social media to enable sharing information orally amongst technologically marginalized groups is closely tied to the ways that meanings about personhood, or what being a person means, are translated in technology design. I support this claim by reflecting on efforts to enable users in a low-income, rural community in South Africa to record, store and share voice recordings. This provides examples of the ways local communication practices were translated through 'logics' about personhood that are located outside of the target community. I propose such translations limit the affordances of social media for the different genres, forms and elements of communication that contribute to sociality in many rural African communities. Reflexive analysis of this sort can increase sensitivity to the effect of assumptions embedded in platforms for sharing information. It is also integral to my wider commitment to show the importance of Africa's intellectual legacy and contribute in moving the centre - a phrase taken from Ngũgĩ wa Thiong'o (1993), who insists that liberating people from constraints of nation, class, race or gender requires plural sites of human creativity. Thus, I begin by relating Thiong'o's theory to 'post-colonial' discussion in the field of human-computer interaction (HCI) to introduce translations, made through Euro-American centres, that might bias insights about social media in Africa and limit the positive impact of design. I then indicate aspects of oral practices that translations might neglect because they are located in certain communication cultures.

\subsection{Logics about personhood embedded in social media and studying social media use}

To control a people's culture is to control the tools of their self-definition in relationship to others.

Ngugi wa Thiong'o 1986: 16

Kenyan novelist, dramatist, theorist and activist Thiong'o (1986: 16) writes that language mediates our very being: 'between me and my own self; between my own self and other selves; between me and nature' (1986: 15). Merritt and Bardzell (2011) introduced his theory to the field of HCI to explain the inseparability of communication and culture, how semiotics of media are laden with assumptions and the potentially disruptive and alienating effects of imposing meanings on societies through media. However, they did not specifically refer to logics about personhood or how social media can act as 'sets of verbal signposts' (Thiong'o 1986: 153) that mediate people's sense of self and relations with others.

Meanings embedded in popular social media, such as Facebook and LinkedIn, privilege an individualist logic where personhood exists prior to interpersonal relationships. Facebook users, for instance, first create a profile before they can 'friend' and can limit how other users represent their identity by censuring posts, comments and photographs. Such a logic suits the modernist premise of networked individualism (Castells 2004), or a network of separate people, who are existentially alone and have autonomous agency. The axis in an individualist logic about self, however, differs from the collective ethic pervading communitarian philosophies attributed to many African societies (Hallen 2009). Even moderate views (e.g. Wiredu and Gyekye 1992) argue that as people are born into community they orient towards others, so individual dimensions of personhood are always in interaction with others and/or the collective. A Namibian's analysis shows that some of the ways her compatriots represent identity on Facebook reconcile with a sensitivity to the social production of self but also suggests that Facebook use contributes to changing social constructs (Peters et al. 2012). The effects of disrupting meanings about personhood might have shaped the concerns of parents, authorities and religious groups about MXit, when this text-based chat system for cell phones became popular amongst young people in urban, low-income areas of South Africa (Chigona et al. 2009).

To theorize about personhood, African philosophers refer to Africa's diverse oratures or systems of oral performance from everyday sayings to specific rituals, in which people attain selfhood. For instance, discourse on personhood in South Africa often refers to 'ubuntu', an isiXhosa and isiZulu word, which relates humanity to the existential interdependence of humans or, approximately, 'I am because we are' (see also: Bidwell 2010; WinschiersTheophilus and Bidwell 2013). The most communitarian interpretation of this part-whole relation views community as primary and personhood as derived. That is, a community defines a person's personhood because communal reality precedes individual experience (see: Ikuenobe 2006). In this sense, personhood is a mode of consciousness that is interconnected between people (Mkabela 2005) who each owe their 'existence to other people, including those of past generations and his contemporaries' (Mbiti 1990: 141).

Biases towards individualist or communalist logics about personhood are, of course, socially situated, since self-reflection occurs relationally. In African societies, people make meaning about themselves, others and the world through older meanings created by ancestors (Mkabela 2005), even if these meanings also incorporate logics from elsewhere (e.g. Marxism) or have been essentialized in strategies to decolonize. However, most of the knowledge in the burgeoning literature on cell phones and social media is not articulated by people who grew up or live in 
African communities. Thus, as Taylor (2011) critiques more generally, authors tend to assign the qualities they find 'out there' to categories that belong to someone from 'in here'. Taylor (2011) draws on Verran's (2001) analysis of everyday logics in Africa in which she explains that the only way to tell the difference between logics is to translate one logic into the terms of another. Yet by creating differences through Western logics, we generalize reality from our own located view, which undermines 'user-centred' design even if such universalism is not some overt mission to occupy, or 'roll back the darkness...' (Verran 2001: 26) of the foreign other.

Applying logics about personhood that emphasize an individualist self may be valid in studying and designing for Africa's growing urban, middle class but less suited to the majority who do not have bourgeois mobility. In many rural African communities, people's status and roles are ascribed by their social relations and their ties are defined by kinship more than by education or work. Practices, such as compliance or loyalty to a social group, emphasize a logic that 'survival derives from group harmony' (Mkabela 2005: 185). Survival through group harmony is not, however, often a key focus in personal digital devices. For instance, in studying phone use in Uganda, Morocco and South Africa, some authors emphasize how women's individual rights, interests and freedoms are disadvantaged by sharing phones (e.g. Burrell 2010; Dodson et al. 2013), but fewer relate sharing phones to senses of belonging or balancing self and communal interests (Walton et al. 2012). Often analyses relate access to phones, accounts or services and monetary definitions of capital or the 'rational economic man' (Cleaver 2001: 47). For instance, Wyche et al. (2013) associate a Kenyan's comment that 'Facebook is a luxury' with financial costs, but do not note that 'luxury' can also mean superfluity to what really matters.

\subsection{Communication, production and creativity}

Translating communication practices through dominant logics in designing social media might actually contribute to barriers in access by amplifying economic differentiations. Thiong'o links the way languages express social relations to the means of production and writes that controlling communication controls wealth. Control of wealth may not have been President Obama's intent when he said, during his 6-day 'tour' of Africa, in 2013, that stronger African economies offered the USA 'somebody to trade with, to sell iPods to, airplanes, all kinds of good stuff'. Yet, 'stuff', like iPods, not only embed certain logics about personhood but also the logics of consumerism that are vital to, what some authors from Africa call, the 'predatory' (Irobi 2008; Coetzee 2013) profit of the 'corporate tribe of the West' (Thiong'o 2009a, b: 22).
Efforts to design social media platforms for sharing information in developing regions are usually framed in ideas about information democracy. These often overlook links between the individualist self and neoliberal economics. In fact, as Irani et al. (2010) claim, we rarely contest the role of corporate power in influencing the meanings embedded in devices. Many would concur with Thiong'o (2005: 20) that 'progress and development need to be measured from the standpoint of those at the bottom of the mountain and not those at the top'. Yet, despite this ideal, our actions can be complicit with systems that contribute to widening gaps between rich and poor, and urban and rural people. For instance, I disagree that South Africa's cellular telecommunications monopoly value-prices services for markets that can afford their tariffs (Bhagwat et al. 2004), but I recompense low-income participants in studies with those same providers' airtime. Like others in HCI, I align with politically powerful commercial market actors (see: Irani et al. 2010) whilst aiming to avoid doing so.

Selling the 'good stuff' reproduces a history of making colonies consumers of colonizers' products, often manufactured from materials from the colonies, such as minerals extracted from central Africa in devices like iPods. The 'good', in the stuff exported, also rehearses a rhetoric that ICTs from overseas 'empower' African nations that cannot develop without this help (Irani et al. 2010). Thus, political, economic and cultural infrastructures of communication arbitrate many African people's ability to cooperate in production and their confidence to create. Thingi'o (1986: 17) proposes that African people sense that technologies are not their own products and some reports support this claim; for instance, Liberian users told Western designers evaluating a public display that they 'know [Liberian] government cannot do that' (Smyth et al. 2010). Imposing a language, Thiong'o (1986: 3) writes, can 'annihilate a people's belief in their names, in their languages, in their environment, in their heritage of struggle, in their unity, in their capacities and ultimately in themselves'. When people theorize and articulate who they are through somebody else's language, not only are they defined by that language, but their intellect is vulnerable to critique when they do so. These are troubling issues for those involved in building Africa's capacity in technology production since Western software methods, tools, programming languages and environments, used in all types of curricula, are embedded with non-African communication practices.

\subsection{Oral practices and the selfhood of a community}

Thiong'o's sensitivity to the effects of controlling communication is a consequence of the suppression of his 
literacy in his home language, Gikuyu, and his efforts to emancipate people through Gikuyu. When he realized his first book in Gikuyu was read aloud in the cafes of Nairobi, he began to write novels to be performed and co-author dramas, and many of these works link oral practices to communalist logics. There are many scholarly examples of the ways oral practices in Africa foster community and express logics about personhood but, before indicating some, let's reflect on the word 'community'. External political powers may categorize a people as a community, say based on geography, and inhabitants may adopt the label even if they do not have communalist social orders (Cook and Kothari 2001). Thiong'o (2009a, b) discusses how colonial oppression used community categorizations instrumentally, but of most significance to him was members' consciousness of belonging to one community as distinct from another. This consciousness relates to values and practices that form 'collective and individual images of self' (Thiong'o 1993: 146) and are expressed in oral practices. For instance, Thiong'o learnt that cooperation was the 'ultimate good in community' through the stories that Kikuyu 'peasants' told as they worked in the fields together each day. Their narratives were metaphors for real-life struggle and their characters had qualities that were either 'truly human', such as concerns for others, or 'man-eat-man', such as individualism and hatred of what was good for the cooperative (Thiong'o 1986: 10).

Learning to recognize, mimic, assemble and handle a community's communication forms, genres and other elements is basic to membership. Thiong'o's own community theatre endeavours gave palpable form to, and embodied, an ethos of democracy, since audience members played varying roles and often become part of the action as critics and/or co-performers. He explains that drama, song, dance and mime were central in rites that reinforced social structures and marked 'different stages of growth and responsibility' in pre-colonial Kenyan communities (Thiong'o 1986: 36). Some societies continue to assign specific roles to people who represent a community and carry the voice of ancestors in critiquing decisions, while many interactively co-author texts between generations (Kaschula 2002; Okephwo 1992). Banal utterances also foster connection in collectivities in Africa. Naming techniques celebrate people's extension or representation of the family, clan and/or lineage to whom they owe their existence. Circumlocution and repetition extend interactions between people; a well-known refrain promotes participation in chorus and reply to someone else's utterance; and, people explicate meanings of oral formulations collectively (e.g. Berber 2005). Communities also use regulated oral compositions to sanction behaviour, resolve disputes and dissent, manage deviance, rectify wrongs, ridicule, deride and critique. Disciplinary and adversarial oral practices often avoid overt verbal confrontation, which Turner (2007) relates to the sensitivity of people in communal African societies to feelings of embarrassment, shame or rejection.

Some technology studies in Africa show relations between oral practices and social rights and duties. For instance, phone use in Kenya is effected by elder sons' social and cultural obligations to facilitate family information flow (e.g. Oduor et al. 2014). However, often phenomena linking technology use, oral practices and social roles are assigned to other analytic categories. For instance, Gorman et al. (2011) note an oral user's disinterest in learning to use a talking book in a usability evaluation in rural Ghana but do not elaborate on her expectations of her grandson's help to use it.

\subsection{Translating oral users through a writing paradigm}

In framing his theory for HCI, Meritt and Bardzell (2011) focus on Thiong'o's concern for the social and psychological effects of imposing a language through written signs. They illustrate ways that media embeds culture by referring to verbal and visual languages in the interface of MOSES, a system Western developers designed to support reconciliation in post-conflict Liberia (Best et al. 2009, 2011). MOSES designers sought to enable people to make and watch videos in public kiosks, and Meritt and Bardzell (2011) discuss mismatches between the hierarchical menu, buttons and voice prompts and participants' responses in a prototyping exercise. They propose that when 'the visual semiotics differ enough from the surrounding culture' then 'errors' attributed to users contribute to a sense of inferiority and can disrupt local meanings (Merritt and Bardzell 2011). For instance, they quote observations of interactions with a paper prototype and vocal instructions:

'we found that users almost always pressed whichever button was announced first, without considering the other choices. Ostensibly, they were not understanding or recognizing the conditional part of the statement, and treating it as a command'. (Merritt \& Bardzell 2011: 4)

The emphasis on visual signs and linguistic meaningmaking by Merritt and Bardzell (2011) and MOSES' designers reflects a paradigm that arises in the writing culture in which technology design is situated. Although Merritt and Bardzell (2011) do not mention it, Thiong'o was acutely aware of written-versus-oral differences made in certain writing cultures. Many scholars of African oratures claim our graphocentricism devalues oral modes. Writing systems have epistemic status in the West, as exemplified by Ong's (1982) reductive theory that accredits 'civilization' to the cognitive internalization of 
writing. Of course, writing systems have many merits, and people have a right to written literacy in their home language; but not all the virtues attributed to writing systems are indisputable. Ascribing the virtues of multi-vocality and plurality to writing does not account for the way that political and economic systems privilege certain genres (Moolla 2012). Indeed, the common definition of literacy is an ideological normalization that favours certain types of literacy, such as those used in formal schooling (e.g. Medhi et al. 2012).

The logics of our writing culture shape a paradigm that orders the ways we observe and analyse oral users, articulate their needs and translate these into reports and technologies. Technologists designing for oral users, in Africa and other regions, draw on the differences that Ong (1982) makes between the formulaic, alogical, prosaic or experiential thinking of illiterate people and the objective, logical, abstract and analytic skills of literate people. However, by translating oral practices through the logics of certain writing cultures, this valueladen, difference-making conceals skills. Actually, surveys, ethnographies and experimental studies show that literacy alone is not responsible for great shifts in cognitive functioning and that scribal systems, reading and writing activities and pedagogies each contribute their own specific effects (e.g. Scribner and Cole 1981; Hull and Schultz 2001). African oratures are replete with abstract and complex structures, vocal imagery and deliberately obscure formulations (e.g. Berber 2005), which conflicts with Ong's model of the cognitive functioning of oral users. Indeed, some scholars propose that language use in Africa manifests a special sensitivity to the ways that language works (Finnegan 2007). The continent has the world's greatest linguistic diversity and most polyglots, often produces new languages, like Krio and Fanagalo, and routinely 'code-switches', as strikingly exhibited by South African soap opera actors who fluidly alternate between three languages within a conversation.

Scholars of African orality have long said that written modes obstruct analysing oral communication and obscure skills that people use to work with information and create and express ideas. Consider, how to report interviews 'out there' a researcher from 'over here' translates between languages spoken and also between the genres of interview and report. Authoring in English for 17 years, Thiong'o came to eschew writing his thoughts first in English and instead translated only after determining the details of the probable situation of each Gikuyu expression. Yet, whilst approaches to oral users may allude to genre (e.g. Ladeira and Cutrell 2010), like the broader field of HCI (Lopisteguy et al. 2006), they have not harnessed the diverse elements of speaking practices to guide designing interactions.

\subsection{Voices and Bodies}

The potential for alienation and negative disruption by visual signs, which Merritt and Bardzell (2011) focused on in applying Thiongi'o's theory, is very relevant to the prominence of screen-based, visual interfaces in contemporary digital landscapes. Yet, screens and visual interfaces integrate models of communication that precede the signs of language to afford and constrain certain types of interactions. For instance, the MOSES system, analysed by Merritt and Bardzell (2011), comprises a screen inside a three-sided sunshade, so only people directly in front can view, hear and touch the interface. Photographs show people face towards the kiosk in ways that seem unlikely to resemble arrangements when people talk about sensitive and complex issues on Liberian streets (see: Best et al. 2009, Smyth et al. 2010). Instead these clusters may more closely resemble the interactions of expatriates who participated in early design in an American university or students in Liberia who evaluated MOSES on computers (Best et al. 2009)—people who Thiong'o (1993: 37) would consider to be 'uprooted from the peoples of Africa and tied to the West'. In fact, reports on MOSES design do not mention practices of talking on Liberia's streets, despite Merritt and Bardzell (2011: 1679) conclusion that a 'culturally situated design process... minimized the potential for deep cultural communication changes'.

Merritt and Bardzell's (2011) difference-making, through visual signs and linguistic meaning, is not unusual in HCI. My past research, for instance, noticed that oral narratives ordered information differently when rural Namibians recorded and watched video (Bidwell et al. 2011b). If, for example, participants described a herb used in medicine whilst in the bush or yard, they tended to say symptoms or causes of ill health first, but if they discussed herbs concurrently with, or just after, watching video, their narratives started with herbs not health. Some participants in these studies, however, criticized constraints that video imposed, and a traditional healer insisted that we always engage in some activities without visual recording, such as learning about herbs by walking together in the bush (Bidwell and Winschiers-Theophilus 2012).

Emphasis on visual signs and linguistic meaning typifies a linguistic determinism that suffuses Western models of cognition (Henkel and Stirrat 2001: 160). Guidelines for oral users based on Ong use cognitive processes to explain stylistic elements, such as verbal rhythms, pauses and repetition (e.g. Sherwani et al. 2009); pay scant attention to qualities of interactions between speakers, listeners and settings (e.g. Pitula et al. 2010); and, entirely omit the thinking and knowing constituted in physical manipulation, movement and sensory-motor memory that HCI more widely considers (see: Klemmer et al. 2006). This 
emphasis may reflect how technologists acquire and embody their literacies. Gesture-based interactions with devices remain peripheral to typing and Western pedagogies still tend to detach inscription from body movements so children learn to copy the letter's visual form not the gesture creating the form (Ingold 2007). Perhaps this explains why analyses of oral users neglect bodily literacies. For example, Medhi et al. (2007) suggest that illiterate people recognize meanings in drawings better than photorealistic images because drawings contain less information but do not consider that they also depict traces of hand movements.

An emphasis on visual signs and linguistic meaning in translating insights about oral users into statements about technology may neglect practices that are vital to making meaning about personhood and might even be socially divisive. Oyewumi (1997, 2010), for instance, claims that Western visual logics caused gender hierarchy, which was not an organizing principle in Yoruba society prior to Nigeria's colonization. Certainly, language has meaning, nuance and 'suggestive power beyond the immediate and lexical', Thiong'o (1986: 11) writes, and Gikuyu children learnt 'the music' of language as much as its content. His novels also profusely describe non-verbal sounds, silences and changes in resonance, tone and pitch. Scholars of African orature describe many other ways that extra-linguistic communication and meta-communication involve the body, from gestures to weeping, and Thiong'o himself notes that dance, mime and song were most dominant in telling the story of resistance to colonial repression.

\subsection{Exploring translations}

This article reflects on the emphasis of logics about personhood manifested in technology design that limits the potential of social media for sharing voice-based information in rural Africa. I introduced how difference-making, by translating African oral practices through EuroAmerican logics, involves the paradigms of certain writing cultures and can obscure practices of sociality, meaningmaking and information transfer. I surmised that Western emphasis on visual signs and linguistic meaning might bias analyses towards individualist logics about personhood and used Thiong'o's writings to propose that oral practices in Africa richly mediate concepts about self. To consider the ways these issues play out in reality, I examine translations in designing and deploying a system for people in a set of rural villages, who call themselves a community. My analysis learns from Australian science historian Helen Verran's (2001) account of different logics in using numbers in Nigeria. I am neither African nor bilingual and the oral practices that animated my early childhood in Africa happened 40 years ago, 7,000 kms north of the region referred to here. Thus, I distinctly acknowledge my role in translations and seek to avoid asserting authority through scientific distance (see: Mkabela 2005; Verran 2001). Further, I wish to insist that although I live in Africa I am not 'holier-than-thou' with respect to the status quo or endowed with any ability to know the ways that the isiXhosa-speakers with whom I learnt should know themselves. Rather by describing translations, like Verran, I seek to prompt agendas for doing research differently.

I reflect on activities that aimed to enable inhabitants of Mankosi, in South Africa's Eastern Cape, to record, store and share voice files using a portable display. The activities are organized according to dimensions that Irani et al. (2010) offer to guide reflecting on the contexts that frame studies and interventions in settings 'out there', not entirely as a chronological process. Thus, after introducing the setting and prototypes, I describe engagements with inhabitants to understand their needs and then how we represented and abstracted from these encounters to articulate requirements for technology. Next, I present examples of the ways these requirements were translated into statements about technology and summarize use of, and interactions with, Audio Repository in Mankosi. I consolidate reflections, and relate these to the literature already introduced, to expose translations that are biased towards individualist logics and limit the availability of social media for sharing information by neglecting elements of communication that contribute to sociality. Finally, I consider ways to rebalance logics about personhood and move the centre of design to enable more symmetrical translation, and their vital importance in enabling the political in media for sociality.

\section{Place and prototypes}

Mankosi, in rural Nyandeni municipality, is one of the Eastern Cape's economically poorest areas. It comprises 580 households in 12 villages that are spread across $30 \mathrm{~km}^{2}$ of hilly land. Between 500 and 900 people live in each village, though the number is hard to verify as people may move between homesteads and between villages, cities and mines, for work and school. Families of up to five adults and seven children live in homesteads comprised of clusters of thatched, mud-brick rondavels, an occasional tinroofed 2-room dwelling, an animal corral and a garden for subsistence crops. People have extensive kin across villages, and everyone knows the homesteads of families in their village. Domestic life is not enclosed in homesteads, which connect, by foot-trodden paths, to communal pasture, forest, taps and dams where people graze animals, make mud-bricks, tend plots, and collect grasses for thatch, firewood and water. Most people walk, a few occasionally 
ride horses or donkeys. There is only one bus, which leaves at $5 \mathrm{am}$, takes up to $2 \mathrm{~h}$ to traverse Mankosi and does not go to all villages. Households survive on $\$ 200$ per month, from government grants and payments from remote family members.

This article focuses on a prototype deployed on communally shared tablets, located at two sites in Mankosi, that aimed to respond to the problems that the Xhosa inhabitants have in using technologies to communicate within their community. Audio Repository enables users to record, share and listen to voice files, directly on the shared tablet or via their own low-end Bluetooth-enabled phones. For fourteen months before introducing Audio Repository, I studied local communication practices and deployed and evaluated another prototype, MXShare, developed by UK researchers (Bidwell et al. 2014b). MXShare also aimed to assist local communication and runs on tablets to facilitate asynchronous communication, as well as using MXit, a real time chat service. As inhabitants have no access to mains electricity, we deployed two solar-powered, cell phone Charging Stations, designed in Cape Town and re-designed in Mankosi (Bidwell et al. 2013a). The trial of Audio Repository ended 2.5 years ago, and we subsequently deployed another iteration, Our Voices, which run on three tablets and enables sharing files between tablets when they connect to a wireless mesh network (Bidwell et al. 2014a). However, I do not focus on Our Voices here and discuss MXShare only in terms of its influence on Audio Repository.

\section{Engagement}

I frame our endeavours in ethnographic action research (EAR), a methodology that links research to communitybased media or technology initiatives in real-world situations (Tacchi et al. 2003). EAR seeks to detect, articulate and solve communication problems in the target community, which answers to the call by Irani et al. (2010) for thinking of design as learning amongst all those participating not a process where designers formulate needs and measure outcomes. However, whilst mutuality is our goal, it is not yet our achievement. The target users in our studies did not initiate invitations to design a communication system; rather I involved myself via contacts with people who are not from Mankosi. I was introduced to the area in 2008 (Bidwell 2009) by a researcher who had worked on technology projects with TransCape, a nonprofit organization based in south Mankosi (Tucker and Blake 2008). This enabled using TransCape's premises a year later for workshops to inform the design of a mobile digital storytelling application, MDSA, that we thought might be widely useful to users without access to computers or high-end phones in sharing life experiences and expressing their imagination digitally (Bidwell and Reitmaier et al. 2010).

Work on MDSA in Mankosi was limited to design workshops and evaluations, but I extended our relationship with TransCape by writing a funding bid with UK-based researchers who developed MXShare and Com-me, another digital storytelling application for more sophisticated phones (Bidwell et al. 2014b; Frohlich et al. 2012). My role in that initiative was to generate information about local needs and deploy and monitor prototypes, so I lived in Mankosi. Although each Charging Station charged up to 20 phones a day for a year, few inhabitants used either digital prototype (Bidwell et al. 2013b). Thus, I contracted Thomas to develop Audio Repository, as he had experience in Africa and developed MDSA, and I ended up living in Mankosi for over 2 years between November 2010 and April 2014.

\subsection{Local researchers and other inhabitants}

EAR explicitly emphasizes the role of community members as fellow researchers, and a team of Local Researchers (LRs) from Mankosi mediated data on inhabitants' communication practices and inhabitants' knowledge about our studies. LRs generated data, advised in design and translated linguistically and culturally. We formed an initial team of five young men, based on recommendations by an inhabitant who had worked on prior technology projects elsewhere in Nyandeni (Tucker and Blake 2008) and over the next 2 years recruited five women. LRs were aged 17-27 years and lived locally at the time; six of the ten had spent $90 \%$ of their lives in Mankosi and rest had spent at least half their lives in Mankosi or nearby. Most LRs are textually literate and had more formal education than many local people; three had completed high school, one has certificates in basic ICT literacy and two have university degrees. However, like most isiXhosa-speaking people locally, LRs have had little paid work before and some, including the youngest, earn their household's income. We allocated tasks based on the LR's personal disposition, interests and confidence in linguistically translating and created and refined data instruments and design activities in sessions that began when I convened the initial team. Thus, LRs routines, problems, values and aspirations shaped data generation and prototype deployment. One LR, Jay, visited Cape Town to discuss with Thomas design issues and first versions of Audio Repository (Reitmaier et al. 2012; Bidwell and Siya 2013). They spoke of the contrast of the city and Mankosi (Bidwell et al. 2013a), of Thomas' experiences in designing and evaluating MDSA (see: Bidwell and Reitmaier et al. 2010; Reitmaier et al. 2011; Reitmaier 2012) and Jay's experiences in trialling and teaching 
inhabitants to use MXShare. They also spoke about how Audio Repository would be introduced.

From the start of our endeavours, TransCape was eager we involve the Community Association, but Community Association members and LRs insisted we consult Mankosi's Tribal Authority. The Tribal Authority mediated most decisions in deploying the Stations and tablets, and thus affected use of MXShare and Audio Repository, but our respect for protocol permitted us to engage with other inhabitants and, later, focus on women in the subsequent iteration (Bidwell et al. 2014a). Tribal Authorities are responsible for local governance of $36 \%$ of SA's population but are separate from other political and administrative bodies. Colonial governors appointed Headmen from Chieftainship lineages, over 150 years ago, to oversee districts and Headmen inherit their role patrilineally. In Mankosi, the Tribal Authority consists of the Headman, 12 Sub-headmen, one for each village, and messengers. The Headman and Sub-headmen's homesteads are sites for local administration from hosting meetings to notarizing proof of residence papers. The Headman is paid a small government stipend but, like most inhabitants, he cannot afford to connect to mains electricity although he is amongst the few who can afford to send children to school in a city.

\subsection{Scheduled encounters}

LRs and I engaged with inhabitants in different types of scheduled encounters including meetings with the Tribal Authority and other inhabitants; workshops in which people learnt to use prototypes and discussed design issues; and, individual and group interviews about use of phones and prototypes. We began by seeking approval to experiment with systems that might benefit Mankosi, and similar communities, by supporting communication in and between villages. Subsequently, we met with the Headman, and any elders with him, over 40 times. First, we met at his or our request to discuss plans, problems or ideas in designing, trialling, maintaining and extending communication systems, and then, according to customary governance, he held meetings with the wider community.

Before launching Audio Repository, I observed or participated in fifteen meetings with community members in the Headman's or Sub-headman's homestead. Usually, this was part of the Headman's weekly meetings that address Mankosi's internal issues and/or host counsellors or municipal officers. Between 20 and 100 people attended, $60 \%$ of who are male and $60 \%$ older than 30 years. People sit according to gender and age, with women and younger men on the ground sometimes speaking quietly together. To speak in the meeting, a person must first raise a hand, stand and remove his hat if he is a man. Nobody interrupts. Meetings, like other planned engagements, rarely started at the slated time, and we often waited hours for people to arrive and then half an hour more as they greeted each other. Mankosi's inhabitants oriented the style, focus and timing of conversations in meetings and, whilst LRs and I discussed beforehand appropriate responses to issues we predicted would arise, I often felt my performance was directed by those gathered.

In meetings, between November 2010 and March 2011, I asked inhabitants where and how to situate Charging Stations and tablets (Bidwell et al. 2013b). After long discussions about access, security and operation, the Tribal Authority proposed two sites, $2.5 \mathrm{~km}$ (25-mins walk) apart: in the homesteads of the Headman, at Ngcobo, and a Subheadman, in Ridge-Mankosi's poorest area. We formally launched Stations and MXShare when UK researchers visited at separate events in each village attended by some 40, mostly older, people (Bidwell et al. 2014b). The Headman and Sub-headmen spoke and I responded to community concerns about the systems, and then, we provided lunch and LRs explained how MXShare worked and interviewed attendees. Over the next 6 months LRs facilitated seven workshops, lasting 2-4 h, with Tribal Authority and Community Association members (22 men, two women) on using MXShare, whilst I observed.

Scheduled encounters with inhabitants also included diary studies and interviews, individually and in groups, with 200 people. For some interviews, LRs worked independently, and for others, with me or a UK researcher when she visited (Frohlich et al. 2012). LRs began by interviewing 141 people in 11 villages about phone ownership and use (Bidwell et al. 2011a, b). LRs interviewed in homes, shebeens, along roads and paths and at football matches. These interviews showed the prevalence of using a free Callback service, so another LR interviewed 16 more people about their use of this service (Bidwell et al. 2011a, b). A UK researcher also generated data on the use of feature phones in $8 \mathrm{~h}$ of interviews inside the homes of Tribal Authority members in group or individual sessions (Frohlich et al. 2012). She asked 28 feature-phone owners, mostly under 30 years, about media stored on their phones. Three months after deploying the Charging Stations, LRs and I interviewed six women (age 27-69 years) and four men (age 22-38 years) living near one Station. We also interviewed six male soccer players, in their twenties, about their phone use, explored how the tablets and phones might support the league and observed interactions with a corpus of locally created audio commentaries, photographs and videos of matches we uploaded to the tablets.

Diary studies generated data on the ways people manage mixtures of communication in their daily routines by reviewing phone use across periods of 4-10 days. These involved an LR and I undertaking individual or group 
interviews at the start and end, and LRs undertaking 72 short individual interviews in between. We began with 6 male and 6 female, low-end phone owners (mean age 48 years), half of whom are illiterate ( 2 women; 4 men). Participants told LRs about themselves and the person on the other end for each event: call, SMS, Callback or deliberate missed call. We also undertook diary studies with 10 younger low-end phone users (mean age 21.5 years) and for four of these we interviewed over MXit, a text-based, real time, chat service that is many orders cheaper than SMS.

\subsection{Unscheduled and indirect encounters}

Because we lived locally, LRs and I engaged with inhabitants in many unscheduled ways. We often observed communication practices by participating in them and had impromptu encounters at deployment sites. I watched operation and use of the Charging Stations, tablets and MXShare in visits to sites for meetings and monthly checkups. I also made more focused observation, in the first 5 weeks and again 3 months later, for a total of $80 \mathrm{~h}$ on different days of the week, times of day and interviewed 40 people who left or collected phones at Stations (Bidwell et al. 2013b).

I indirectly 'encountered' inhabitants in various ways, through types of auto-ethnography and LR's logs. LRs recorded who charged phones each day at Stations in notebooks. LRs and other inhabitants video recorded over 50 items which featured some 60 people, aged 14 to 80 years, in interviews, conversations, storytelling and presentations. They recorded in or outside people's homes, on grassy hills, along roads at the soccer pitch and in church.

\subsection{Linguistic translation}

Although my rudimentary understanding of isiXhosa improved, usually during meetings, interviews and workshops, I spoke in English, most others spoke in isiXhosa and LRs translated. Language translation adds a temporal quality to engagements, not least because isiXhosa can take three times longer than its English translation and some elders spoke a formal 'old-style' dialect that LRs considered carefully to translate. We recorded observations in handwritten notes and sometimes video or photographs and also video-recorded interviews, workshops and some meetings for later translation. Usually, LRs translated video within a few days and did so by video recording themselves watching and listening to the video item they were translating. They paused the item every so often to speak aloud in English what they had heard to the camera recording themselves. Thus, as well as LR's voices the translation video recorded LRs facial and bodily expressions as they watched and listened to the item. In some instances, LRs also typed transcripts. LRs also video recorded their own isiXhosa role-plays to explain the project and oral consent to participants in studies.

\section{Articulation}

Abstracting concepts for use in design from experiences in engagement involves interpreting or inferring the needs, wants and desires of designated target users and local opportunities or constraints (Irani et al. 2010). Here, I organize concepts thematically using some ethnographic details.

\subsection{Orality}

The overall need to support oral practices emerged from my ethnography in a district adjacent to Mankosi (Bidwell 2009; 2010); design workshops for the original MDSA (Bidwell and Reitmaier et al. 2010); and, many subsequent engagements in Mankosi (e.g. Bidwell et al. 2011a, b; Bidwell and Siya 2013; Bidwell et al. 2013a, b, 2014b). Inhabitants devote much time talking to greet, support, learn, gossip or debate and an ambient orality pervades daily life, as they call between homesteads, sing in gardens, whistle to animals and chat whilst they walk to communal resources (Bidwell et al. 2013b). The vast range of video that inhabitants recorded focused on the speaker not the visual setting, which prompted UK collaborators to call it 'talking heads'. The importance of voice conflicted with design emphases for MXshare (Bidwell et al. 2014b). Of the 970 media items Bluetooth-ed to the two tablets during MXShare's trial, $65 \%$ were photographs, $28 \%$ audio files and $7 \%$ videos, but this was mostly because MXShare was optimized for photographs and most local phones could not send audio through it. UK collaborators' commitment to the content of visual media may have inhibited their appreciation of local orality. They did not think LRs' video-recorded oral translations were as useful as simultaneous print transcripts, and their analysis focused on deriving categories pertinent to development (e.g. health, small-business) to guide designing story templates (Frohlich et al. 2012) in ways they had done in India (Frohlich et al. 2009).

I linked the need to support orality to inhabitants' phone use and their preference for voice calls over other services, especially if they are older. For instance, SMS comprised only $1.4 \%$ of older people's phone use in diary studies. In interviews, people said audio recording was a useful feature of phones (Bidwell et al. 2011a, b) and some used feature phones to record local performances, events, conversations, jokes and stories, and music from the radio 
(Frohlich et al. 2012). Workshop participants liked to practise using MXShare by recording themselves speaking or singing, rather take photographs, and the preferences of men to record their speech and of women to record song align with oral practices in ceremonies and church. Further, some participants agreed to audio, but not to video, recording interviews.

\subsection{Identity}

Many inhabitants can trace their ancestry over five generations across Mankosi, and adjacent districts, and people have enduring links that suggest that communality constructs self (Bidwell et al. 2013b). Some links manifest concretely, such as ancestors' graves in homesteads or places that were once homesteads; some manifest in undertaking the same practices in the same places, such as gathering wood as a woman's female line or in-laws have done before; and, some are reproduced in practices of praying, dreaming and ceremony that recognize ancestors as agents and adjudicators and protectors of the living. Indeed, inhabitants are identified by their relationships with others in Mankosi. Their names recall relations with ancestors through clan, in families by birth order, marriage or parenthood and between peers in shared rites of passage. Names express relations between past, present and future, like a story does, and people use this information in ordinary practices. For instance, an older man said that the formality of a clan name in a Callback might express that the sender was 'really desperate' (Bidwell et al. 2011b), and LRs used different names for the same inhabitant when logging whose phones they charged (Bidwell et al. 2013b). Inhabitants are familiar with each other, and their everyday visibility contributes to senses of belonging and security, expectations of cooperation and performing certain roles.

Inhabitants' videos suggested that orality closely associates with their values and senses of identity and belonging. Often the way LRs' retold what they watched and heard when they orally translated video intimated different genres. Some genres linked to identity, such as the way older women tell folktales to children and grandchildren at night, and men exchange stories of their life experiences during the day. In one recording, an 18-yearold LR discussed, in isiXhosa, with two male friends (F1 and F2) the talent for poetry that F1 had inherited from an uncle who took him to ceremonies, where he learnt 'to stand in front of people and talk to them'. The LR's videorecorded, English translation explains:

"This student [F1] have good talent, the other day he surprised us and showed his talent to us. I asked about his talent in future and F1 said he wish to be succeed in bright colours, to be known in South Africa as a poet, so that the humanity of people can grow, so that we cannot go to other cultures like West culturessomething like that.

And F2 ask him so [is] he fighting for his culture or his language? And he [F1] said he want to fight the Westlife he want to fight for Xhosa so that someone can distinguish between English people and Black people.

And I said to him [F1], his ambition is good and in our days we like to live the Westlife most of the time, and I ask him what will he say to the people who live the Westlife although they don't belong in that culture? And he [F1] said, you know for something that you adapt to other cultures easily and ignore yours is what we are on with now. And there is no help for us.... And he [F1] said the most important thing is to raise his voice, and he said he does want to raise his voice about writing ... he want to raise his voice."

Interview and translation, Mvuzo Tshemese, November 2010, Ngcobo, Mankosi.

\subsection{Inclusivity}

Better supporting orality seemed to offer a way to widen access to digital communication. Older and/or illiterate people often said in interviews that they were 'not educated to use the phone' and $40 \%$ of adults in Mankosi, including Tribal Authority members, do not read and write. Illiteracy is not stigmatized and does not affect daily life as it might in urban areas since print and reading and writing materials are scarce. Some illiterate people said in interviews that they can recognize 10-20 names or numbers or had diaries in which they were written down, but inhabitants also said they did not use free or low cost services as they could not 'read properly'. Almost all phone owners, in interviews and diary studies, used a free Callback service that younger and/or literate people appropriated to send very abbreviated messages (Bidwell et al. 2011a). Some younger people with Internet-able phones used MXit, and other youngsters were eager to learn to use this text-based service. However, use of MXShare articulated that MXit did not suit older people; over 10 months MXShare hosted only 135 MXit conversations, mostly, made in workshops by participants learning to use the system or between young LRs (Bidwell et al. 2014b).

I related inclusion to enable people to send and receive voice messages whether or not they owned a phone. LR's initial interviews showed that $30 \%$ of inhabitants aged over 14 years did not own a phone, that less than half of phones were Bluetooth-enabled and fewer than $15 \%$ enable data access to use MXit or VOIP (Bidwell et al. 
2011a). Those who owned phones were twice as likely to be under 35 years, and most phone owners acquired phones between 6 months and 4 years before. Inhabitants responded positively when I introduced the concept of a shared device in meetings and said, in interviews, that members of homesteads shared phones in which they insert their personal SIM cards. I thought that access to a voice message system might also help people with insufficient airtime credit. Despite favouring voice, most phone users spent on average R7 (1.1 US\$) per week on airtime, as pay-as-yougo subscribers, which permits speaking for only about $4 \mathrm{~min}$ at basic rates (Bidwell et al. 2011a).

\subsection{Reliability in information sharing}

Discussions in community meetings, and the decision to site tablets and Charging Stations at the Headman and Sub-headman's homesteads, articulated that the main priority for communication was for governance and the Tribal Authority and older men were most important in this. Meetings often take $3 \mathrm{~h}$ and can entail walking for over $2 \mathrm{~h}$, and people commented that they hoped communication systems could improve dissemination to those unable to attend. Meanwhile, interviews and diary studies indicated that people do not prioritize using phones to coordinate between Mankosi's villages. Only $13 \%$ of older people's phone use was to contact those in villages a 2-h walk from their own and only $10 \%$ of their phone events specifically arranged meeting (Bidwell and Siya 2013). Sub-headmen and Headman's messengers are the main conduits for information between villages. In meetings, the Tribal Authority's voluntary secretary writes minutes and attendee's details on paper but does not disseminate these, and Community Association members remarked that minutes did not always accurately report what was said. Such practices fuel allegations about the Tribal Authority's 'forgetfulness', inertia and opacity. Several inhabitants, including the Tribal Authority, also said that audio recordings of meetings would 'stop people lying', which approximates to holding people to account on verbal commitments. Together these insights suggested a need to improve the reliability of delivering information.

\subsection{Temporality in information sharing}

I interpreted that improving information distribution did not inevitably imply speed in transmission from temporal patterns in communicating. Workshop participant's positive opinions about MXShare related most to storing media, not to real time chat. Various factors shape local perspectives on the timeliness of information (e.g. Bidwell et al. 2013a). Firstly, there is a regular co-present contact within villages, which is tuned by the pace of life, as people walk to undertake their daily tasks (Bidwell et al. 2013b). Older participants in diary studies had seen, or predicted to see, just under a third of the people with whom they had interacted by phone within a day of that interaction, usually within their everyday tasks. Secondly, immediacy is not a high priority; for instance, when asked in interviews why they liked Callback, only $12.5 \%$ of all participants' responses referred to its immediacy but $69 \%$ referred to its lack of cost. Thirdly, people do not expect that phone use affords instant communication and some $50 \%$ of phone owners' diaries recorded at least 1 day when they did not use their phone at all. This often relates to cost and inhabitants pay to charge phones as well as buy airtime. Before the Charging Stations were introduced, most people charged once a week, at spazas (small shops) or shebeens (informal bars). Thus, people restrict calling to cheap times, switch off phones to conserve charge and leave phones to charge for 2 days if charging is free (Bidwell and Siya 2013). Expectations about instant communication are also affected by the instability of cellular network connections and environmental effects on call quality in places where people undertake daily tasks. Fourthly, access to phones via an intermediary effects temporality; for instance, an illiterate mother always waits for her daughter to walk home from school to read aloud and reply to her messages, and inhabitants often said that before they owned a phone they were contacted via the phone of someone else who would walk to bring the phone or a message to them. Finally, people are accustomed to maintaining enduring connections despite limited contact, due to a long history of circular migration when, for example, a man might come home only once a year during his 30 year employment in the mines.

Thomas provoked my reflection on deliberate qualities in communication. After opening meetings, the Headman usually listened silently until the end, when he stated how an issue would be resolved or discussed further, meanwhile people attended carefully to the speaker before speaking. In interviews, it was also clear that inhabitants, especially older ones, tend to plan phone use and interact with phones in their homesteads and rarely whilst walking, in transport or in meetings.

\subsection{Bridging the skip generation}

I inferred a need for the system to bridge older and younger people's use of digital technologies as information flow in Mankosi has been disrupted by the 'skip generation' phenomenon. Skip refers to the dramatic population decline between the 20 and 44 years old because people of parental age are those most likely to work in cities and mines and also die from illness (related to access to health care and HIV prevalence of $29 \%$ ). I observed, in meetings and 
daily life, structures that differentiate information sharing. For instance, over 700 different people of all ages came to charge phones at the Station but men over 40 years were most comfortable visiting the Headman's and younger people did not prolong their stay. Some videos, that LRs recorded, described old practices that encouraged friendship only between people at similar life stages and conversation only between people of the same gender and discouraged talking between unmarried and married people. Customarily, people learn from their immediate seniors in daily life, as depicted in the proverb 'ask a Buffalo of those who are behind you when hunting' which means that a younger person must ask a more experienced person (Dlutu-Siya 2013 pers.com). People formally learn from elders at key life stages, and manhood school and tutelage of newly married women continues today. These practices might explain why younger people said that they can feel uneasy teaching elders to use cheap services, and in workshops LRs often interacted with tablets or phones for their elders. Older inhabitants said their grandchildren would take and upload photographs to MXShare for them, though few did, and they would store photographs of deceased people so that orphaned children could recognize their ancestors. Older people made more calls, thus, I thought that a system that supported elders' oral practices would enable them to send voice messages to younger people.

Diary studies and interviews showed that people prioritize using phones to communicate with and exchange support with those they share close bonds, either in their own villages or far away. However, older and younger differ in their pursuit of a remote presence in others' lives. Frequent communication was a key attraction of MXit to younger people who, in diary studies, logged on 3 or 4 times daily to leave brief messages or chat with family, friends or people they did not know in cities. Older people, however, perceive use of MXit as playful and unrelated to local coordination. Younger people made deliberate missed calls, 'buzzes', and used free services, such as Callback, for fun and to let contacts know they are 'thinking about them'. Their higher print and technological literacy also enables them to abbreviate English and mix isiXhosa and English words to appropriate services in potentially ambiguous ways. In contrast, older people prioritize practical purposes and were more selective in using Callback services, often noting that learning to use it was hard, that they sent Callbacks with unambiguous meaning, and buzzed only if they had little airtime and wanted to talk or meet.

\subsection{Privacy}

I articulated a need for a very simple system of registration, since complexity and technical difficulties had meant only
24 inhabitants registered for an account with MXShare, mostly during the launch or in teaching workshops (Bidwell et al. 2014b). However, needs for privacy and expectations about visibility conflict. Participants in workshops approved that they could store and share media privately on MXShare, and their accounts were accessible only in the presence of the registered phone, even though they are familiar with each other's phones. On the one hand, inhabitants' decisions about handling phones and locating the Charging Stations in highly visible ways addressed their concerns about theft, or accusations of theft, of phones, batteries and airtime. LRs, aiming to avert theft, also suggested that they say that shared equipment can track users. Meanwhile, trusted intermediaries assist people with low print literacy; close family members know each other's PIN codes (often birth years); and, participants in workshops did not attempt to hide their passwords from others. On the other hand, LRs were troubled when 'adult' content was uploaded to the public mode of MXShare, and I interpreted other desires for privacy. In interviews, some inhabitants noted with dismay that people covertly took photographs of others without consent and phone owners said phones helped to make their lives more private and had changed their patterns of calling or walking between homesteads, so now they chose to 'shout-out' or buzz a deliberate missed call depending on their reason to communicate.

\section{Translation}

Audio Repository manifests a set of statements about technology derived from interpreting concepts about communication needs through the legacies of mobile technologies. Some statements inherited from those already embedded in MXShare and Charging Stations, and I translated others from concepts in my ethnography, inhabitants' practices and remarks in meetings and workshops. Some statements were translated by Thomas, in discussion with an LR or me and from my requirements specification, and still others were embedded when LRs and I introduced Audio Repository. Obviously, concepts were also affected by isiXhosa-English language translation, which implicates my interactions with LRs. Here, I focus only on issues pertinent to relationships between social media, orality and logics about personhood.

\subsection{Tablet-based system to support oral users}

The system's primary functional requirements were to record, store and share voice files that inhabitants could access with or without phones. I sought to rapidly deploy a working prototype to allay frustration with MXShare 
within research timeframes, so I framed requirements in the platforms given to the community to trial MXShare: two 7-inch Samsung Galaxy Android tablets, owned by the whole community, and 31 Nokia 2330 classic and 2730 phones, owned by Tribal Authority and Community Association members. Thus, Audio Repository inherited from MXShare by translating a need to share, display and store media using a communally shared tablet. It also inherited the concept of interfacing users' phones with the communal tablet from MXShare (Bidwell et al. 2014b), which itself had inherited from the design of Storybank for India (Frohlich et al. 2009) and Bigboard in Cape Town (Maunder et al. 2008). All these legacies had a formative assumption that digital communication in and between villages, enabled by communal displays, would benefit inhabitants.

My translation emphasized audio because MXShare's bias towards visual media had not supported oral practices or illiterate users. Yet, whilst almost all meetings and interviews I attended occurred outdoors, and often meant wind sounds adversely affected audio recording quality, I did not enhance the tablet with costly microphones. Further, developing and updating a system using solely vocal interactions involved computational demands exceeding those afforded by tablets in low-electricity conditions. This limitation inherits from universal low investment in aural technologies, which acutely lag advances in technology for the visual mode. I settled on a visual interface to create, share and listen to audio files because even older participants in workshops easily recognized and interacted with the icons on MXShare's graphical interface (Bidwell et al. 2014b). However, rather than only focusing on icon and interface form, we also leveraged the tablets' touch interface's affordances for bodily aspects of communication.

\subsection{Primacy of personhood-acquired-in-community- relations}

We sought to give ontological primacy to a communalist logic about personhood which emphasizes that self is acquired through relations between people. I considered starting with household groups, as we had done in representing accounts in MXShare (Bidwell et al. 2014b), but this did not accommodate the many links between households. Thus, I began by abstracting all possible types of relations between Mankosi's inhabitants to identify, say, a woman as a granddaughter, daughter, sister, half-sister, types of in-law, widow and girlfriend, as companion to collect wood with, a music buff to exchange tunes with, or a member of a particular church, and so on. I soon realized the infeasibility of predicting all relations a priori to scope the space for Thomas to design interfaces, so toyed with ideas that inhabitants define relations for themselves based on interpersonal relationship types. However, I foresaw ambiguities and inversions in implementing this logic, not least because of linguistic translation, such as when different inhabitants had said 'I don't have friends' and 'she is my kin so I just pretend to be friendly'. I stuck, unstuck and re-stuck Post-it notes on which I had drawn 'stick-figures', conjoining and unjoining people in hypothetical relations, and sketched charts, whilst reminding myself that nodes and edges in any graph are transposable. There, in Mankosi, with the sounds of village life filtering in and out of awareness, I stared at the first class of Xhosa nouns and related phrases scribbled on paper: umuntu-person singular; abantu—people, plural; umuntu w'ubuntu—human being conceived as an individual by, with/in self or oneself; umuntu mu bantu—human being as socially constituted with/in community or other (e.g. Ntibagirirwa 2001: 66-68).

Muntu means a being amongst beings with intelligence; but $m y$ intellect was utterly stifled by the archetype of a person as an autonomous node. At a hopeless impasse, I resorted to typing a crisp set of functional requirements with the statement that Thomas' tasks included phone calls with me. This specification emphasized capabilities for users to share voice recordings publically, with an individual or a subset of people. I thought that if Thomas modelled the backend database using the canonical entity 'person', or in other words people as a plurality, that LRs and I could emphasize the primacy of social relations, and person as part of a whole, when we introduced the system. Thomas translated my requirements for functions to enable users to restrict access to their recordings and define specific people with whom to share, by modelling 'Person' and 'Group' as entities, where each instance has an independent identifier (Fig. 1a). Users who register for an account can store audio files; send/receive files to/from other registered users; and, create and enable access to groups of registered users.

\subsection{Text-based registration}

To ensure easy registration within constraints, I opted, reluctantly, for text entry. Thomas designed a simple registration that included a photo, taken using the tablet, and fields for the user's first and second names and password. Many illiterate inhabitants, use PINs on their phones, recognize important numbers and gain assistance from intermediaries. Thus, I indicated that the password should be numeric; however, Android is designed for literate people and defaults to character input so passwords were alphabetic or numeric (Fig. 2). 

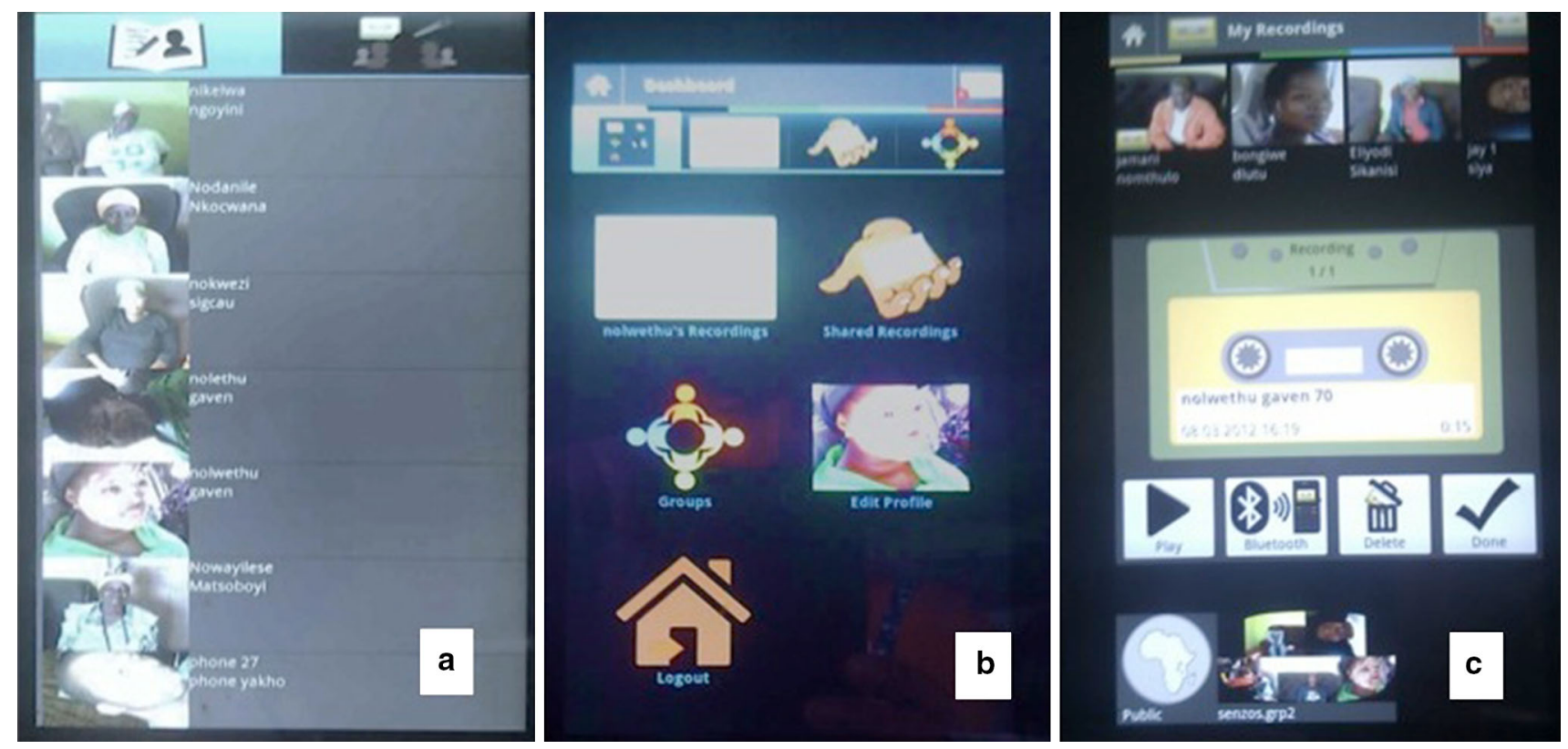

Fig. 1 Interfaces to Audio Repository. Users find their account by scrolling vertically through profile photographs (a); Select functionality using the homescreen in their account (b); and share recordings by slowly moving the cassette icon of their recording upwards to other single users or downwards to 'public' or 'groups' (c) (colour figure online)
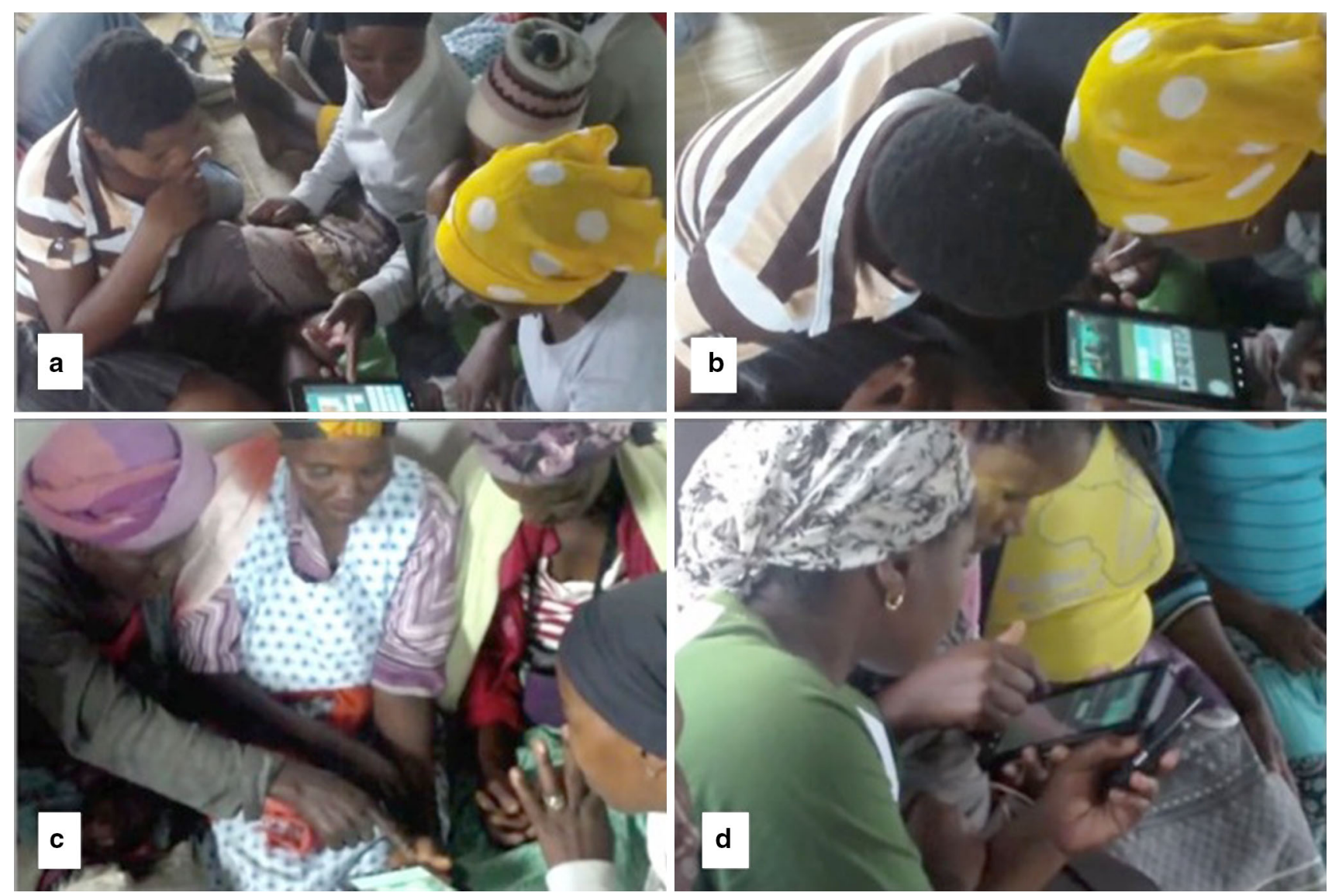

Fig. 2 In workshops to introduce Audio Repository, women (including an LR) guide each other to login to an account (a); replay a recording (b); record audio (c); and share a file across bluetooth to a phone (d) (colour figure online) 


\subsection{Access without phones and by Bluetooth}

I sought to ensure that users could record, listen and share files on the communal tablet without owning a phone, unlike MXShare. However, younger people feel less comfortable at Tribal Authority sites and are also more likely to own Bluetooth-enabled phones, so I thought they could use the inbuilt recorder and speakers on their own phones to record and listen to their messages and upload/download these to the tablet via Bluetooth. I also thought this might extend distribution by enabling users to share voice files across Bluetooth between the tablet and their phones and between phones. Thus, Thomas put great effort into ensuring Audio Repository interfaces with a wide range of low-end Bluetooth phones, including Nokia models since some $60 \%$ of local phones are Nokia (Bidwell et al. 2011a, b).

\subsection{Relating the visual and gestural mode}

Thomas elaborated gestural aspects in designing interactions for the tablet's touch interface. He modelled some visual icons on the interface he had developed for the MDSA, which we evaluated in rural South Africa and Kenya (Bidwell et al. 2010; Reitmaier et al. 2011), and also applied Hutchins et al. (1985) principles for direct input (Reitmaier et al. 2012). For instance, the recording interface is based on a large cassette tape icon, and once the user presses the record button, the interface displays on the tape: the user's name, the word 'Recording' in red font, a timer, and a VU-meter to indicate the system is recording. The interface and interactions for sharing files is a special example of the way Thomas related visual and bodily interactions, inspired by deliberate qualities in speaking and passing messages. In discussion with Jay, the LR who visited Cape Town, he symbolized sharing with an icon of a palm-up open hand that leads to the sharing screen when pressed. In the sharing screen, users find the accounts of people to share their recording using a standard gesture to scroll horizontally through profile photographs, but to share a file a user long-presses on a tape icon and slowly drags a small copy of the tape rather than selecting the target with a single click to accelerate interactions. When the user lifts his/her finger, the tape drops onto the corner of the photograph(s) of a target user/group or the public icon, where it stays to show the recording is shared. Users scroll vertically through profile photographs to find their account as inhabitants recognized people's photographs in MXShare. To assist identifying files, we used a basic folksonomic strategy by displaying those with whom a user shares a file.

\subsection{Translation in introducing Audio Repository}

Irani et al (2010) focus on translations during design, but LRs and I introduced Audio Repository so we also directly affected many inhabitants' first encounters with it. We launched Audio Repository during community meetings, planned by the Tribal Authority to discuss maintaining the Charging Stations after the 1-year trial ended (Bidwell et al. 2013b). Then, we ran seven workshops with 50 inhabitants and afterwards sought opinions about the system by interviewing 23 people, in four groups. We taught 33 women inside the new unfurnished rondavel of the Subheadman's daughter-in-law, and 14 men and two women, in the Tribal Authority or Community Associations, inside the Headman's office. Thus, unlike most engagements that articulated requirements, we ran workshops indoors.

Based on experiences with MXShare, we anticipated that each workshop would include between four and eight people. Prior to the first workshop, LRs and I discussed ways to prioritize personhood-acquired-in-communityrelations. We planned to first introduce the recording interface in public mode to convey Audio Repository's communal intent, and then discuss groups to convey the primacy of social relationships in sharing. We planned to iteratively create individual accounts for participants and a group with a name that represented something about relationships between members. Despite our planning, practicalities arose that meant to include all workshop participants we elevated a logic of community-constitutedby-pre-existent-persons over personhood-acquired-incommunity-relations.

We began workshops with the Tribal Authority, as planned, but as members had very different speeds of learning, LRs preferred to teach in pairs/threes using two tablets even though only one tablet was to remain with the Tribal Authority (Fig. 3). Thus, we registered Tribal Authority members' profiles twice but exposed them to the idea of creating and inviting to groups just once. After introducing Audio Repository to the Tribal Authority, we arranged workshops with inhabitants in Ridge. To our surprise, twice nearly 30 women arrived when we expected six. With three LRs and three tablets, we asked the women to divide into three groups based on whom they were most likely to share audio recordings but this did not produce similar sized groups. Thus, to focus teaching on the most relevant functionality, we congregated women who did not own phones, those who owned phones, and those who owned Bluetooth phones (Fig. 2). Only four women could see the tablet at a time, so, as for the Tribal Authority, LRs first created accounts for each woman on two tablets to ensure they were registered on the tablet left at Ridge and the one they used to practice in the workshop. As planned, we suggested participants use Callback to alert others that they had shared a recording. We thought this was better than a 'buzz' because low-end phones do not always display calls received whilst they were switched off. 

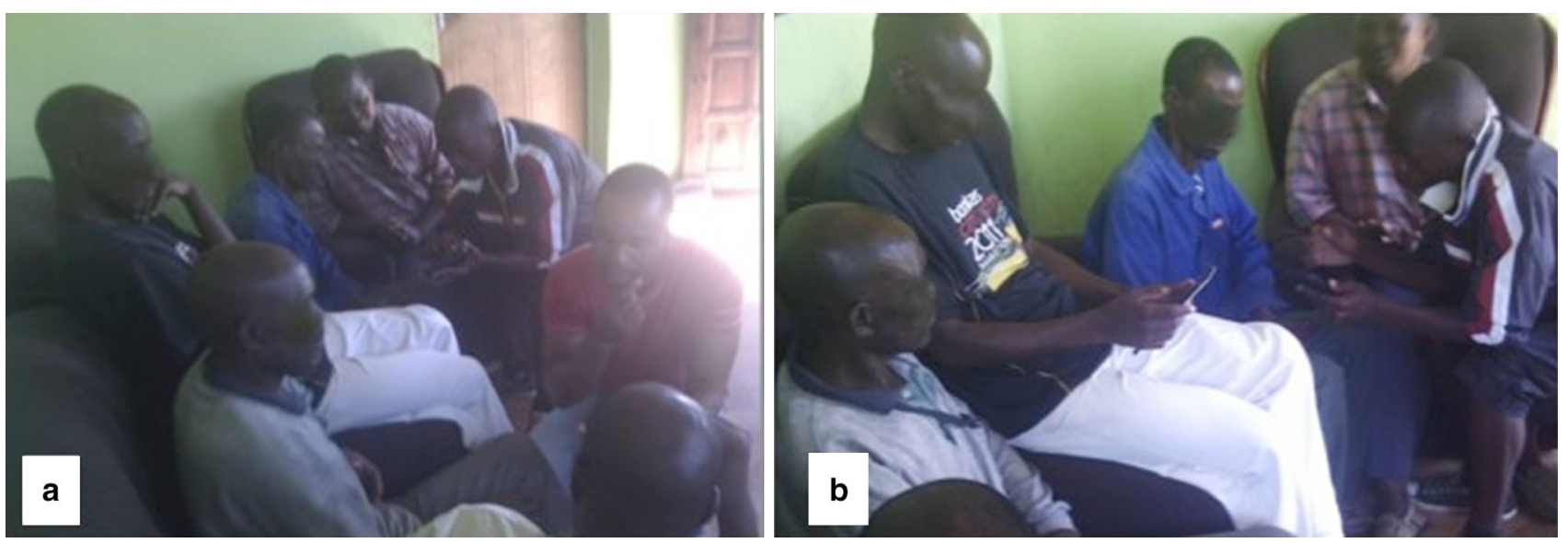

Fig. 3 LRs teach Tribal Authority members to use Audio Repository in two groups inside the Headman's office (colour figure online)

\section{Interaction and appropriation}

Male and female inhabitants of diverse ages and technological and print literacies were very enthusiastic about Audio Repository and readily learnt and taught each other to use it in workshops. The Tribal Authority, most of whom do not speak any English or have print and technology literacy, learnt and the Headman was particularly eager, even though he had refused to try MXShare. Registration, even with many people in workshops, presented no problems and people found their own, or others', accounts using photographs. However, whilst Audio Repository enabled community-wide information sharing more than MXShare, its use in the 10 months trial was not as predicted.

\subsection{Co-present recording}

In workshops, women said that they would leave updates about issues and events or messages for family members, that some said might become mementoes, but this did not happen as access to the tablet was restricted. The Charging Station at Ridge, overseen by women, was damaged and not redeployed until after trialling Audio Repository (Bidwell et al. 2013b). The Headman moved the Station in his homestead and began to charge the tablet using another system; so, people who came to charge their phones did not easily access Audio Repository. In fact, Audio Repository was used mostly to record and listen to meetings and to store files exclusively in the Headman's account: 35 of meetings, a song from the radio, a discussion about a tablet useability problem and 12 used to practice or that contained no audible sounds. Recordings were usually made in community or Tribal Authority meetings that address local issues, host counsellors or municipal officers, resolve tribal law cases or involve a ceremony (Table 1) and included meetings the Headman attended on 17 different days.
Table 1 Number of recordings in community meetings grouped into broad genres

\begin{tabular}{ll}
\hline Content of files & $\begin{array}{l}\text { Number of } \\
\text { files }\end{array}$ \\
\hline $\begin{array}{l}\text { Communal resources: land issues (2); land and sand } \\
\text { (2); community trust; community trust records (2) }\end{array}$ & 7 \\
Cases: Insult to TA; insult related to circumcision; & 8 \\
pregnancy damages (2); building without TA consent & \\
(2); Drunken fight; fight at the soccer game; fight & \\
within a family & \\
Narratives, notices, problem-solving: How royalty & 9 \\
conferred a Sub-headman his role; Sub-headman's; & \\
dream about an ancestor (2); Circumcision and & \\
health; Insult at initiation school related to inter- & \\
community rivalry; Wage delays for community & \\
project workers; Wi-Fi pilot; Charging Stations; & \\
White man's request to build & \\
Guest speakers and ceremony: Social support grant & 5 \\
(2); municipality (2); welcome speeches at a & \\
preschool opening &
\end{tabular}

Mostly, there were less than five recordings a month but in 1 month there were 17, and there were 2 months without any recordings.

Of the Headman's recordings, $22 \%$ were shorter than 10 mins; $70 \%$ of 10 mins to $1 \mathrm{~h} ; 7 \%$ of $1-4$ h. Only two files recorded a whole meeting, and files usually recorded one main topic. Some $70 \%$ of separate files that were made on the same day recorded discussions of different topics. When separate files were recorded on the same day, at most two files recorded the same or an allied topic. The Headman recorded weighty topics in meetings that he said needed to be 'referenced' in the future. Once we realized that Audio Repository files recorded sensitive issues, we decided that one LR should listen and summarize their contents but omit the details of who, why and where from her report to me. A third of the files recorded information 
about issues affecting inhabitants, a third recorded 'cases' of tribal law, $20 \%$ recorded events in Mankosi or elsewhere hosted by the Chief or municipality. The Tribal Authority said that others were impressed by their advancement in using Audio Repository at Chief's meetings, and five Headmen (governing around 50,000 people in total) had asked how they too could have an Audio Repository. The Headman said Audio Repository was vital as key Tribal Authority members had been less available than usual. For instance, one day he was alone when another Headman came to contest Mankosi's boundary so, whilst a child went to alert his secretary, the Headman used Audio Repository to record the exchange.

The Headman decided an issue warranted recording based on who spoke and 'what they start to say'. Files recorded discussions of protocol and inherited authorities and some of this dialogue occurred in recordings that contained disciplining speech acts by, and apologies to, the Tribal Authority (Table 1). Some of these files also related to various disputes within Mankosi or with another community, which were judged in Tribal Authority cases. A third of files recorded discussions about environmental resources, and some also contained dialogue about the community trust, which is expected to manage income from resources (Table 1). Speakers use different oral styles for testimony, argument and apology in cases; commentary of customs and experiences; and, notices and debate about communal resources. We were able to differentiate between voices in 33 files and found an average of 5.4 different male voices per recording. Often, $40 \%$ of attendees at community meetings are women; however, men represent families, and $88 \%$ of voices in files were male and $78 \%$ of files contained only male voices. We discerned an average of 2.9 different females in files containing female voices. There were two files that recorded only female voices amongst a set of five in which a municipality speaker spoke about children's social grant during the opening of a preschool.

Some $51 \%$ of files were recorded outdoors, and the wind was audible in a third of these, which made understanding speech in two files impossible. Some $21 \%$ of files also recorded music, children or other ambient noise. A young man carried the tablet between each person as helshe stood to speak; thus, many files recorded long pauses in speech and sounds of movements that connoted the relative orientation of recorder and speakers and distance between speakers. The recorder's movement and the tablet's size also afforded visibility and twice in meetings men, including Community Association members, resisted recording as their permission had not been sought. Early in deployment people said that a person who records another owns the audio recorded, if they share this media, all recipients own the media and that there would be 'a fight' or 'trouble' that entails negotiating with the recorder, if a person contested sharing a recording of them by other inhabitants, that all recipients own shared files.

\subsection{Co-present sharing}

The Headman called the tablet his 'witness' and said he had not deleted any file, used Audio Repository to remind himself of topics after meetings and 'to deliver information' to the Tribal Authority. However, he rarely shared recordings to phones, individual accounts or the group we created for the Tribal Authority. Indeed, no one created a group during the trial. Instead, the Headman listened along with other members, and logged into his account so his secretary could listen alone to enhance minutes of meetings. He found a part of a recording easily, using the time bar that displays when the audio plays to move through the file, but this functionality does not work for recordings of over $1 \mathrm{~h}$. As our strategy to identify specific file visually based on who shared them was ineffective the Headman looked at the date on the tape, which was incorrect for $50 \%$ of files because it had been reset when the battery drained.

After 8 months, the Headman asked us to delete temporary accounts made in workshops on the Tribal Authority's tablet because other Headmen had reproached him for having too many female friends. Some $70 \%$ of accounts were women, and $50 \%$ of these appeared in a block because Audio Repository orders profiles alphabetically and husbands often rename their wives with first names starting with 'Nom'.

\subsection{Voices, bodies and meanings}

Various interactions suggest that Audio Repository affords and traces spatial qualities of communication and that some patterns and arrangements can invoke meanings. The tablet's portability and audio microphone position meant that files recorded relative orientations of recorders and speakers, and pauses and sounds when a man carried the tablet between people in meetings (Fig. 4). Video showed people huddled around tablets, bent their bodies together to listen and held the tablet for each other (Fig. 2b). They pointed to the screen to assist others and some made rhythmic hand gestures to depict interactions. Bodily interactions with the tablet can afford felt-experiences and the Headman made a playful analogy between 'riding an unfamiliar horse' and the tablet when it was reset to a Cyrillic script after its battery drained. Physically sharing the tablet suggested that interacting with touch interfaces tangibly trace social relations and the vertical display of alphabetically ordered photographs also interacted with local meanings. 

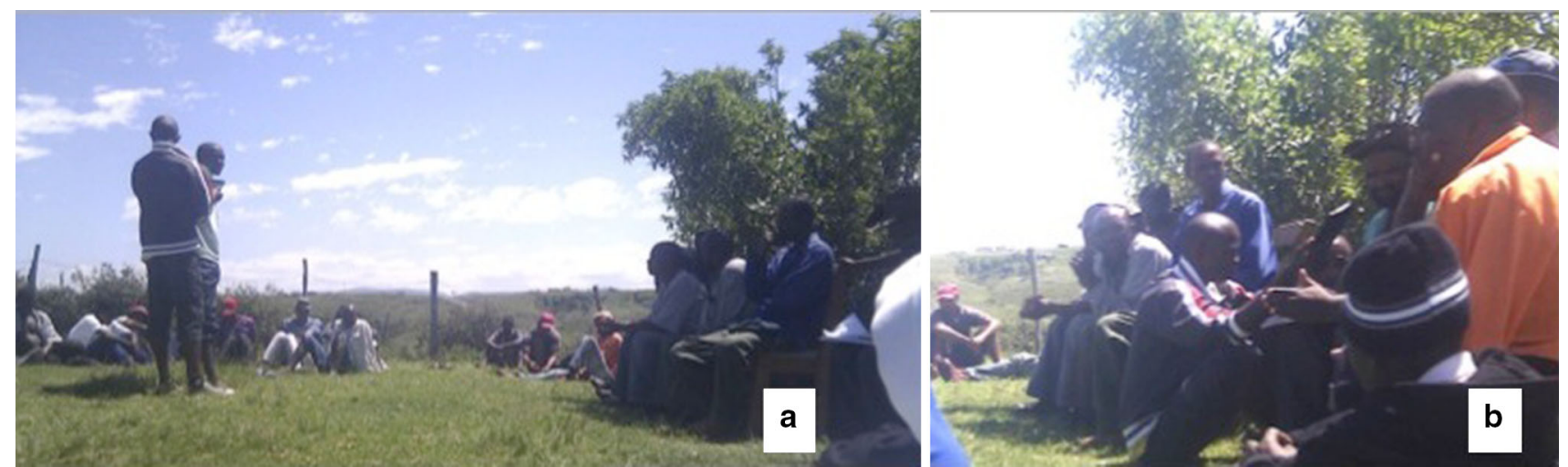

Fig. 4 In meetings the Tribal Authority appointed a young man to carry the tablet between speakers. Here an LR was appointed to carry the tablet between some young community members who were asked

Many interactions with, and remarks about, Audio Repository articulated relations between bodies and sociality. In workshops, women sat on grass mats huddled around tablets, which they held for each other, and men, sat on chairs, bent their bodies together to listen (Figs. 2 and 3 ). The ways they physically shared the tablet resonated with the slow drag interaction for sharing files that was inspired by qualities of speaking and passing messages. In workshops, men and women often made hand gestures to depict interactions as they taught others to use Audio Repository, and the Headman related gestures and social roles to the display of profile photographs in saying that a photograph directly above his own implied disrespect as it depicted a young man using a rap-style gesture 'over' his head.

\section{Translating personhood}

Mankosi inhabitants' interactions with, and appropriation of, Audio Repository offer insights into translations that affect the availability of social media to oral practices in rural Africa. On the one hand, the Headman's control of access and selectivity in recording and sharing expresses his role in the community and the power he inherits. On the other, inhabitants' co-present interactions with tablets in certain social situations suggest that recording and listening to voice files on a communally owned, portable touch screen device can support interactions that construct personhood. Here, I relate logics about personhood to translations in design and deployment that affected information sharing.

\subsection{Objectifying personhood}

As in Sect. 5.2, translation in design and development, explains, foundational logics about personhood in African to explain a situation to the Tribal Authority (a) who then responded to the issue of concern (b) (colour figure online)

philosophy and in hegemonic schema for relational databases are incommensurable. Attempting to apply African logics about personhood, that I had read or heard in English, further dichotomizes personhood-as-pre-existent or personhood-as-acquired. My dogged, but ineffectual, insistence on the ontological primacy of personhoodacquired-in-community-relations detached logic from practice. I separated the acquisition of personhood (and/or the constitution of community) in Mankosi from, as Verran (2001:24) writes about her initial, relativist approach to logics of number, their 'embedded and literally embodied way of contributing to the ongoing life'. To build theory Verran originally rendered the Yoruba numeration system as an object in charts, paragraphs of English words, print and papers, but, on reflection, she explains the 'patterns made in spoken words contributed to the life of the markets of Yorubaland, so that it was scarcely possible to separate human body and numeral' (Verran 2001:75). I re-entangled my abstraction of a communalist logic about self into words, graphs, clumsily conjoined stick-figures and other peculiar representations and, by re-embodying personhood in ink dots, lines and scribbles on small scraps of paper, I too 'literally objectified it' (Verran 2001:75). Our respective theoretical dis-entangling and practical re-entangling rendered systems and logics as objects 'whereas before our interventions there was not an object at all' (Verran 2001:75).

Perhaps knowing, unconsciously, that reifying relations that constitute personhood into an object would not make any logic commensurable with practices, I aborted my stick-figures, crumpled my papers and abdicated responsibility to Thomas. The specification of what the system should permit users to do focused on actions and invited discussion, but also re-entangled these abstractions in typed print that Thomas then materialized into bits of code and bytes of data. Thomas abstracted a more refined schema from my specification that articulated community- 
constituted-by-pre-existent-persons in the core database ontology. I hoped that the order of introducing functionality would re-entangle a logic of personhood-acquired-inrelations, but ordering in workshops retold the same logic, that personhood is pre-existent and community is derived, as embedded in MXit, MXShare and the database.

Eventually, I realized that dichotomizing between logics using the logics in which I am versed was a contrivance and, like Verran (2001:23), 'the logical schemas I had described were like designs for machines that could never actually work'. Hardly surprising, then, that Xhosa-speaking graduate students in informatics warmly and politely refrain from replying when asked about commensurability between logics about personhood and part-whole or singleplural relations in database schema. Mankosi's inhabitants do neither and both logics at the same time, just as Verran (2001) concluded for African logics of number.

In implementing workshops, LRs and I did, analogously, as some teachers in Verran's (2001) account of applying a science programme in Nigerian primary schools-we digressed from our plan. According to a logical personhood schema, we presented Audio Repository as communityconstituted-by-pre-existent-persons. Yet, during workshops, I felt untroubled that ordering was unfaithful to a logic of personhood-acquired-in-relations. To the contrary, I was delighted that participants learnt to use Audio Repository and engaged with each other, barely interrupted by workshop ordering or interactions with the tablet. There in his office the Headman, with the Tribal Authority and LRs, sat around tablets on worn chairs, their bodies seemed comfortable and LRs adapted their gestures to elders and protocol as they normally would. There in the rondavel, amidst the sounds and movements of babies, children, bottles of Coke and biscuits, women sat clustered, bodies often entwined, helping each other, laughing and enjoying camaraderie. Applying Verran's (2001:23) description to our workshops: as in the wider sphere of life in Mankosi, things went along in ordered ways that were at once both and neither personhood-as-pre-existent and/or personhoodas-acquired.

I have great respect for LRs who improvise in real-life situations to facilitate learning. In workshops, they patiently, caringly, reverently and jollily taught people of all ages, genders, print and technological literacies and language abilities, who turned up in numbers and at times we did not plan. The LR's capacity to translate systems of knowing is not a conscious, deliberate choice between alternative logics of personhood. Rather practices that already produce, and reproduce, roles and identities according to Mankosi's social system, fused with the ordering of workshops, ontology of databases, affordances of, and representations on, tablets. The practicalities of the workshops meant we created personal accounts on Audio
Repository; so all who attended first encountered the representation of personhood as-pre-existent. However, they did not seem to interpret accounts as autonomous. Rather people related the self that was represented on a communal tablet to roles and identity in the community; for instance, the Headman's role affected meanings about the presence of so many women's photographs and of the photo of the young man gesturing irreverently. Meanings about the presence and spatial arrangement of photographs emerged when interactions with Audio Repository entangled with inhabitants' practices.

\subsection{Reifying out the going alongs}

The visual semiotics of the profile photograph arrangement emerged in contingent entanglings of Audio Repository and tablets in practice, not from a static linguistic logic that was manifested by the interface. This starkly contrasts with the way design reifies the relations that constitute practices in the processes that map events, agents and beings to computer systems and model interactions. Consider, for instance, the schema of engagement, articulation and translation, around which this article is organized. Irani et al (2010) do not imply that these categories are discreet phases but offer them as devices to refract politics, power relations and onto-epistemological commitments. My account describes politics in decisions to site the tablet and power relations between the Headman and others, but does so by separating them from the flow of engaging, articulating and translating as we went along.

Designers forever reify in representing activities, artefacts and places. Our reifying binds practices into packages to stabilize them enough to tinker, transport and talk about them; but it also distracts us, theoretically and practically, from the meshing of their constituent relations. I notice this mesh because I adapted to changes in the setting targeted for design as they occurred, from local politics to the weather (Bidwell et al 2013a, b), and I struggled to model a database schema from a foundational logic in ways that reconciled with the knowing embodied as we went along. Reifying makes events into things, that punctuate the continuity of going along, and seduces us into thinking that translating is alike a set of bridges to cross 'the cultural chasm' (Merritt and Bardzell 2011) between logics in deployment sites and design thinking.

In workshops, LRs entangled the tablet and Audio Repository in many linguistic and extra-linguistic elements of oral practices. These improvisations, situated in an unfolding mix of engaging, articulating and translating, were neither logics about personhood-as-pre-existent or acquired. A more suitable metaphor for translation than a bridge across a chasm is, then, a river between. In his novel about villages, either side of 'The River Between' 
Thiong'o (1965) refers to discord produced by imperial 'divide and rule', and the focus of my metaphor is on the way the flow of a river along can connect or split. A river expresses how we participate in forming the world we study; it can carve canyons or deposit sediments, rush or meander, separate or dissolve constituents. No moment within a river is the same as the last or the next. Conceptualizing translation as a river, not a bridge, emerges in realizing, like Verran (2001:38), that collective life is 'a logical going-on in actual times and places'.

Thinking that meaning forms in going along is by no means novel in the Eastern Cape, where in local language 'are we walking together?' can mean, metaphorically, 'are we still on the same page?' (Dlutu-Siya, pers. com., 2012). I often heard teachers say 'sihamba sobabini', in isiXhosa, or 'are we moving together?', in English, in a rural high school elsewhere in Eastern Cape. Concomitantly, inhabitants of Mankosi did not use Audio Repository in ways that fragmented conversational threads. They did not record separate files of each person discussing an issue in meetings, share messages via Audio Repository and then use Callback to alert a recipient, nor did they record voice messages. I should have predicted that they might not leave messages since people rarely use phones to leave voicemail as it consumes airtime they prefer to use to converse (Bidwell et al. 2011a, b). However, my translations, such as in Sect. 4, abstracted talk from going along when I related: orality to inhabitants' phone use; information reliability to remote delivery; and, inclusion to listening to voice files alone. Despite all the hours of talking about unfolding deployments and chatting as we walked along, I barely articulated the way meanings emerged in going along together at all.

Categories that thingify pervade the genres that specify technology. For instance, my analysis thematized 'phone use' and 'inclusion' in articulating requirements and the content of files recorded. Despite techniques to enrich interpretation in design, such as scenarios and role-play, we model information as sets of reified events, agents and objects and not acts of in-forming. These genre conventions influence data about users. Often we interview users 'out there' at many spatially and temporally discrete and distant sites and upwardly integrate the data we generate (Bidwell et al 2013b). Such reifications, particularizations and integrations produce knowledge objects that register but do not absorb life 'out there' as much as they manifest practices of moving, making, using and representing in here'. This situation prevails even when researchers apply more creative methods. Consider, for instance, Method Card techniques used in Rwanda and Namibia to envision technologies and focus design activities. The cards visually represent an interface element or evoke a theme, such as autonomy, security or trust. In cross-cultural contexts the aim of the images is to 'speak to the diversity of human communities' and encourage designers to 'attend to what is important in people's lives' (Friedman and Hendry 2012). However, use of the images tends to forget the practices that reified, categorized and integrated phenomena in designing the cards. Some designers aim to use the cards to 'co-design', but still focus on what participants visually or aurally select and not the ways they communicated by using them (e.g. Rodil et al. 2013). That is, these so-called participatory methods explicitly define, articulate and structure 'local' knowledge practices in external models (Mosse 2001:24).

\subsection{Genres that disembody voices}

...the night of the sword and the bullet was followed by the morning of the chalk and the blackboard.

Ngugi wa Thiong'o 1986:9

The genres used to articulate requirements and specify technology bear little similarity to the genres that Thiongi'o (2013:95) considers closest to the way shared meanings emerge in the 'dialectics of life' in rural African communities. From his school days in Kenya, he was intrigued by the role of collective effort in drama and the progression of actors, from initial imperfection to near perfection, in heightening community. He proposes that audiences identified with drama more when they experienced that actions and actors evolved as a product of collective contributions. Impeding collective meaning-making is a formidable tool to oppress, and Thiong'o (1986:58) writes that the neo-colonial regime imprisoned him not only to punish but also to severe his contact with people and 'stop the emergence of an authentic language of Kenyan theatre'.

Scholars of African oratures repeatedly raise concerns about the ways that transcripts detach texts from their animating contexts and effect bias towards the individualist self (e.g. Berber 2005; Moolla 2012). Script does not inherently preclude collective meaning-making in going along. The teachers I observed, elsewhere in Eastern Cape, asked 'are we walking together?' most when reading textbooks aloud. They read and, often mid-sentence, paused or asked 'and what?' whereupon learners read aloud the end of the sentence or the next. Moolla (2012) writes that '[s]cript in itself does not fundamentally collapse societies predominantly oral' nor 'close the social horizon against which oral societies determine self-perfection' rather the most profound change to the poetries she studied was caused by reconstituting orature in the genres of modernity. Her analysis of transformations in Somalian verse shows that literary qualities of the novel genre mask the oral poet's artistry, and the materiality of 'print capitalism' embodies the individual subject. 
Thiong'o and his peers endured subjugation because the writing system imposed at school did not reconcile with the way they knew themselves through the practices of the community to which they belonged. Merritt and Bardzell (2011) accentuate Thiong'o's remarks about the incommensurability of the visual signs of language to alert HCI to the effects of meanings in interfaces. Yet, their focus on visual semiotics and linguistics in analysing the design of the MOSES system for Liberian users tellingly omits the body. The disembodiment of colonized Kenyans is a repeating trope in Thiong'o's novels-metaphors for severing mind from lived body and dismembering 'the social body' when education and books imposed language (Thiong'o 2009a, b:28). Many interactions and remarks in Mankosi articulated relations between meanings and bodily and verbal actions. Men's gestures as they spoke in meetings responded to each other's body movements; younger people adapted their gestures to elders and protocol; I swiftly learnt from friends' bodily responses to avoid all harsh or critical utterances; and, Audio Repository recorded cases about verbal insults, including some that directly linked male bodies and identity. Yet, despite all the hours, I spent listening and speaking in meetings, workshops, homes and along paths, my specification left our bodies behind. I reconstituted experiences in the genres of technology design that separate meaning, utterance and bodies.

To his credit, Thomas' prompted contemplating tempo, such as deliberacy in speaking, and designed interactions composed of icons and gestures, rather than single clicks, to respond temporal qualities. The interaction style for sharing reconciled with the textures of movements when people used the system together. In workshops, people sat closely, bent their bodies together to listen and held the tablet for each other. They assisted and guided others to use Audio Repository by pointing to the screen as they spoke, and some made rhythmic hand gestures to depict interactions. Meanwhile, audio files traced the movement and relative orientation of recorders and speakers in meetings, such as pauses and sounds when the tablet was carried between people. These insights suggest interactions fused meanings, the sonority of words and the bodies that speak and hear them.

\subsection{De-synchronizing rhythms that are alive and lived}

I have often asked myself whether my delight with inhabitants' engagement in learning to use Audio Repository is merely an emotive attachment with the prototype and iconoclastic critique of technology design's imperialism. Undeniably, my eagerness to share voice recordings was tainted by the ghost of frustration felt when UK collaborators did not engage with inhabitants' oral practices. However, any need for vindication is trivial compared to the profound sense that inhabitants absorbed Audio Repository into alive and lived togetherness, despite the anomalous and impractical logics about personhood presented. At the end of workshops in Ridge, women sang together in thanks, in ways that were so palpably thick with pride in or obligation to human togetherness that I was barely able to suppress tears. In fact, harmonized singing and sometimes dancing became normal in subsequent workshops for Our Voices, the next iteration of Audio repository. We deployed Our Voices on three tablets including one overseen exclusively by women in Ridge. However, despite easy access the women do not often use it (Bidwell et al. 2014a, b) rather they eagerly and repeatedly requested, and engaged in, workshops about Our Voices, even when already familiar with using it (Bidwell et al. 2014a). It seems that, whilst inhabitants sometimes say that they 'act as one', it is the nuances of speech, song, gesture and movement that articulate being together most explicitly.

Couplings between bodies, voices and meanings are more important than foundational, essentialized logics about personhood and more vigorously inspire design. Thomas' engagement with extra-linguistic qualities of orality, in designing touch interactions, reflects his immersion in field evaluations in Kenya and in video of interactions in Mankosi to design the MDSA (Bidwell and Reitmaier et al. 2010; Reitmaier et al. 2011; Reitmaier 2012). He was particularly captivated by video of a workshop in Mankosi in which women recorded a story about unfolding events in a child's morning routine. The women's conspicuous fluidity in taking turns to speak, barely pausing, affected and was affected by their interactions with the recording devices. We all have rhythms, in breath and movement that we tune with speech. Drawing on diverse research from music to neuroscience, Gil (2012) argues that the rhythmic synchrony of bodies and voices is integral to sociality and enables 'being together'. Selfsynchrony supports interpersonal coordination by enabling us to adapt our speech to others and time syllables and pauses as we converse. Gil cites a study in which pairs of participants, in isolated rooms who talked using microphones, finely tuned their body movements to their own and the other's voice. Their rhythms aligned with the language they spoke but concurrent movement also arose even without speech (Gil 2012).

We noticed many rhythmic qualities in speaking and in interactions with prototypes in Mankosi. People's rhythms in interacting with the tablet continuously adapted to each other and this enabled several people, especially women, to coordinate in manipulating the interface, even though the device is not designed for multiple people to touch (Bidwell et al. 2014a). Like a handshake, this joining of people is not just symbolic but the bodily becoming of a 
synchronized whole. Most typographical genres, such as UML models and specifications, do not encapsulate rhythmic qualities and, thus, omit the way personhood is embodied in connections between bodies, meanings and sounds.

\subsection{Bursting bubbles}

Portable devices and mobile applications do not entirely obstruct relations between meanings, sounds and bodies in being together and expressing personhood. Co-present interactions with cell phones (e.g. Walton et al. 2012) and shared access (e.g. Burrell 2010; Dodson et al. 2013) are widely reported in economically poor areas in Africa. In Eastern Cape, people share phones and high school learners study collaboratively around the tablets just as they had done in sharing textbooks in the past. Nonetheless, wellknown conflicts between hand-held screens and proximal settings constrained the places in which people could use Audio Repository together. To introduce Audio Repository, we ran workshops indoors because interactions were affected by sun and wind and, even then, participants strained to hear their recordings amidst the chatter of many women. The wind meant many files recorded in meetings outdoors were muffled and the Tribal Authority had to listen to files in the Headman's office, where women and younger men are uncomfortable. Thus, the tablet's poor microphone and speaker functions disrupted relations between information sharing and Mankosi's everyday outdoor life. Many scholars note that oral practices in communal governance are conducted in the open and Thiong'o explains that practices that maintained Kikuyu social structures always occur in places that were attached to the sphere of community life. He writes that drama 'was part and parcel of the rhythm of daily and seasonal life of the community. It was an activity amongst other activities, often drawing its energy from those other activities' (Thiong'o 1986:37).

Worries about imbalances in supporting individual freedom and symbiotic togetherness have increased in places where digital technologies are more ubiquitous. Kreitmayer et al. (2013) aim to unsettle a dominant idea of the owner of the personal device 'tapping away - silently submerged in their private digital bubble', by exploring environments that promote co-present interactions. They found that adding hands-off large displays increased participants' collaboration around tablets and use the metaphor of 'bubbles' to describe assemblies that support togetherness. Although Kreitmayer et al. (2013) do not cite Sloterdijk's Spheres (2011), they infer a similar theme. We always have a 'togetherness in something', Sloterdijk (2011: 542) writes, as embryos, in families and in close-knit communities. These originary 'bubbles' are unsustainable at large scales so we often seek ways to re-invoke them, such as at dance parties that absorb thousands of people into temporary, rhythmic sonospheres (Sloterdijk 2011).

In Mankosi, music is sometimes heard outdoors and people do sing and dance, but there are many more banal sounds and movements related to daily and seasonal rhythms, cycles and activities, (Bidwell et al. 2013b), all of which constitute an 'acoustic community' (Truax 2001). Marcel Jousse argued that audible and visible movements link people's thoughts and actions. His prodigious work a century ago was only recently translated into English but informed Ong's theory, which continues to influence design for oral users. Whilst both relate cognition to features of speech, such as formulism and mnemonics, Jouse did not share Ong's evolutionary view of writing or his Cartesian treatment of mind and body in which a disembodied intellect separates knower and known. Rather, Jousse related oral styles to people's constant interaction with each other and the world, and proposed that the rhythms of their audible and visible movements reflect micro- and macro- settings (Translation of Jousse 2000). This resonates with Thiong'o's remark about the energy that drama drew from other activities and can explain the fluidity of women in taking turns to speak and interact with devices to record a story about events in a daily routine (Bidwell et al. 2010). Jousse's theorizing about the way our bodies and voices mimic what happens around us in everyday life, suggests that responding to such couplings can produce designs to support 'being with' and 'togetherness' (Sloterdijk, 2011) in digital bubbles for oral and other communities.

\section{Generative creativity to move the centre of design}

The reflections in this article are inspired by books and articles typed in English by a Kenyan, who co-authored drama in Gikuyu, and an Australian who translated Yorubaspeaking Nigerians. They also denote theory written by African philosophers and copious handwritten field notes. Mostly, however, my reflections flowed and bubbled amidst the extra-linguistic communicative qualities of isiXhosaspeaking people in Eastern Cape. There in Mankosi meanings about personhood unfolded in fusions of sounds, gestures and settings as people talked as went along.

My work with LRs and other inhabitants exposed tensions between the relational, ongoing-ness of meaningmaking and the logics of the writing cultures in which technology is designed. When we design for oral users, we reify from oral practice to 'find' knowledge objects and organize 'findings' in genres that separate mind, body and setting; sound and movement; gesture and utterance; and, people from togetherness. These various separations 
limit technology's affordances for qualities of oral practices, such as links to rhythms in everyday spheres of living. Interactive video systems sit inside 3-sided sunshades detached from interactions on streets; Intel's smartphone designed specifically for Africa has a radio but no speaker for people to listen together; the genres of IVFs privilege remote interactions; and tablets deployed in rural schools do not enable multiple children to touch screens together. Provided methods, devices, interfaces and media sufficiently support ordinary interactions in various social circumstances people can manage tensions between meanings generated in oral practices and in design's translations. Managing these generative tensions, however, is not a choice between logics internal to users' minds or between foundational logics, such as individualism or communalism, embedded in symbolic schema, databases or visual interfaces. Rather, managing these tensions involves the ways people, speak, gesture and move in making meaning in going along together; to suggest otherwise is to dismiss the creativity of collective life.

\subsection{Oral practices as political}

... a second epoch of colonization - this time by a universal-humanoid abstraction defined and conducted by individuals whose theories and prescriptions are derived from their history, their social neuroses and their value systems.

Soyinka 1976: quoted in Irobi (2008)

'Life is movement arising from inherent contradiction', Thiong'o (2013:54) writes, and the bubbles in which people are together in rural societies may be bipolar (e.g. Sloterdijk 2011). In Mankosi practices of visibility, solidarity, loyalty, privacy, secrecy, jealousy and tactful defiance of conformity all interlace and all in their own ways enable belonging and security (Bidwell et al. 2013b). Oral practices in African communities are often integral to managing these contradictions, such as public discussion and critique (Turner 2007). Aspects of these practices can be supported by broadcast media like local radio but evidence mounts that access to mobile devices and services amplify differentiation. For instance, the people that researchers selected for an IVF in rural India, by virtue of their affiliations with development initiatives, did not pass on livelihood information to those researchers excluded (Patel et al. 2010). Similar moral orders, hierarchies, financial or text-literacy issues that constrain women's private access to phones in Uganda and Morocco (Burrell 2010; Dodson et al. 2013) probably also limited women's participation in an IVF to share information in Tanzania (Sullivan 2012). Most researchers promote wider access to private channels to address such differentiations (e.g. Dodson et al. 2013), and there are certainly situations when individualizing approaches are best; for instance, in communications that carry high social risks like accessing information about HIV (Ndwe et al. 2012). However, an ideology of individuation, in interventions, affordances of devices and genres of interactions, can also burst the bubbles of coexistence and disrupt the harmony that enables the poorest to survive.

Translating logics about personhood through the logics of certain writing cultures is part of a project of knowledge 'founded upon literacy' (Henkel and Stirrat 2001: 160). This project is reproduced through the dominant genres and modes of modernity in technologies proliferated by the capitalist marketplace. Dominant social media and personal devices, then, materialize a kind of graphocentric colonialism that secedes voice, body and community. Recognizing conflict between this project of knowledge and practices in oral communities is vital, but not merely to inspire systems to support diverse expressions of personhood. If social media is to have a truly democratic, not totalitarian, structure, then it cannot impose the individualist logic of the Western democratic moral order. It must concede that interdependence in an undifferentiated whole, or togetherness-in, are just as valid as an independence from others for the condition of being human. Africanist and Western views on emancipation differ (Oyewumi 2010) and Thiong'o asserts that the real language of humankind is the language of struggle. He referred to South Africa's anti-apartheid movement as a struggle to 'recover a sense of human community' and for humanity 'to save itself' (Thiong'o 1993:150). Most of the champions and martyrs of the liberation struggle were the sons and daughters of the homeland of Transkei, now in Eastern Cape province. In fact, Mankosi is just $60 \mathrm{~km}$ from Qunu, the ancestral home of Nelson Rolihlahla Mandela, the global icon of democracy who held aloft the mirror in which the twentieth century has been looking at itself' (Thiong'o 1993:150). The political of interest here is not the heroism of resisting racist regimes per se, but the value of oral practices in the antagonism needed for plurality of the conditions for being human.

\subsection{Plural sites of imagination}

A true humanism with its universal reaching out can flower amongst the peoples of the earth, rooted as it is in the histories and cultures of the different peoples of the earth.

Ngugi wa Thiong'o, 1993:17

It is easy, Adichie (2006) writes, 'to see poor people as inherently lacking agency and will. It is easy to strip them of human dignity'. Researchers, like me, do this whenever we report on peering 'out there' since our writing erodes the chosen self-representation of the other (Henkel and Stirrat 2001:160). Even in direct transcription, the words of 
a speaker are signed by their writer (Irobi 2008). I often try to tackle this paradox by authoring with LRs (see: Bidwell et al. 2014a; Bidwell and Siya 2013; Bidwell et al. 2013a, b; Bidwell et al. 2011a). Yet, whilst LRs are integral to my knowledge, the genres of articles reconfigure our experiences in essentializing categories and do not let their bodies speak.

Thiong'o (1993) seeks to move the centre both between nations, from its location in the West, and within nations, from the elite to periphery. Adopting a perspective on people in rural African communities as 'guardians of the language' (Thiong'o 1986:45), not feeble beneficiaries of translations through Western logics, offers vast potential for insights about the affordances we need for new types of digital bubbles. The persistence, continual recreation and contemporary adaption of diverse oratures show their efficacy in expressing identity. Africa's tales, poetries, dramas, riddles, proverbs and sayings, and its praises, prayers, elegies, songs and chants constitute a wide array of genres, sub-genres, narrative and lyrical forms. Audio files in our dataset recorded diverse skills and artistry, from stirring speeches at meetings to comical commentaries at soccer matches. They are vibrant and functional arts that far exceed the forms stereotyped by people 'in here' (see: Pritchard and Vines 2013; Harrell 2007) and span genres that in the West are mostly enjoyed by elites, such as poetry. These living forms offer a 'return to the sources of the being in the rhythms of life and speech' (Thiong'o 1986:73) and ways that, as the LR's friend hopes, 'the humanity of people can grow'.

Merely engaging with a 'pluralism of languages as legitimate vehicles of human imagination' (Thiongo 1993:28) will not achieve multiple technological spheres or emancipate oral and aural imaginations. Oratures in South Africa, from hip hop to slam to ibongi verse, appropriate technologies (Kaschula 2004), including social media; but are also constrained by them (Pritchard and Vines 2013). The marketplace commodifies living talent and exploits aesthetic forms to further empower advantaged spheres and, meanwhile, participatory hegemonies impose models of democratic voice without regard for social orders or communication protocols. Harrell (2007) attends to some of these issues in designing GRIOT, a system to implement interactive and generative computational narratives. The GRIOT platform is informed by Nguigi's theory of orature that integrates oral performance in spaces that support shared values amongst participants. GRIOT valuably illustrates that engaging with typically excluded practices energizes innovative and expressive computing practices; yet, applied in a community like Mankosi, it would, again, translate oral practices through the logic of writing culture.

\subsection{Pursuing symmetry}

... until the lions have their own historians, the history of the hunt will always glorify the hunter.

Chinua Achebe and Brooks (1994)

This article linked limitations in social media designed for communities 'out there' to who it is that expresses the relations that constitute personhood and how these relations are translated in design. We trialled Audio Repository longer than other systems designed to assist information sharing in rural communities, but my analyses yields fewer specific statements about technology, such as design implications. Instead, my interpretation indicates the absurdity of clarifying the inadequacy of any design using the same culturally situated and linguistically determined parameters, methodologies and critical indexes that created it. I can only imitate and contradict logics already circumscribed by dominant graphocentric ideology and ontoepistemology. I am tied in a self-referential knot, unable to enable symmetrical translation myself.

Addressing asymmetry in translation must go further than answering Ken Banks' question 'where are African studies of cell phone use in Surrey?', after yet another Euro-American study was presented at the premiere academic conference for digital technologies and development (ICTD'10, London 2010). Currently, we teach African researchers and technologists in the methods, tools and genres of certain writing cultures and make these literacies status symbols. This validates dominant ideology, demotes 'the vernacular tongues of the people' (Thiong'o 1986) and proliferates a 'kinship between scholarship and colonialism' (Thiong'o 1993: 46). If noticing this, and allied tensions introduced here, is to generate futures that differ from the epistemic violence of the past, then we require a very different dialogue. Addressing asymmetry demands situating translations outside of the West's philosophic orders about reality, or what Irobi (2008) calls, Euro-American 'thought-policing'. Such movement involves not just locating design activities in, say, a rural village but constructing designers, design methods, interventions, technologies and interactions through inhabitants' practices. In other words, locating African oralities at the centre of statements is about technology. This goes beyond 'being participated' (WinschiersTheophilus et al. 2012), such as when Mankosi's inhabitants oriented conversations and directed my performance in meetings. To situate statements about technology in the onto-epistemologies of rural African people means governance by, not appropriation of, African theories, categories, particulars, terms, generalizations and African opinions about how these are best expressed.

In Eastern Cape, I observed a young man performing a praise poem that he composed about tablets received in a government-funded, e-learning initiative, during his high 
school's cultural day celebration. He did not perform at the behest of the government's project or, in fact, with a tablet (though many learners in the audience recorded his performance with theirs). Rather, he evocatively verbalized his appreciation for the tablets using stylistic qualities of a traditional praise genre. If my interpretation of interactions in Mankosi, albeit through another set of logics, theories and episteme, has any plausibility, then genres of knowing will privilege bodies as the site of discourse, linguistically and extra-verbally. Perhaps, this will involve discourses that are prevalent in 'selling the story of repression and resistance', such as dance, mime and song (Thiongo 1986: 108), or poems like the young man performed. These oratures have their own languages, metalanguages and methodologies to critique, guide and improve their aesthetics, configurations and functions (see: Irobi 2008) and are integral to Africa's philosophic traditions, which were never limited to purely conceptual aims (see: Gyekye 1987).

It would not be new for African kinesthetic and phenomenological literacies to influence Western thought. These traditions moved from the continent with Moorish, Arabic, Mediterranean and Indian globalizations from the seventh Century, and crossed the Atlantic for 400 years with slaves (Irobi 2008). It would be new, however, to fairly endorse and credit African logics, literacies, genres and modes and refrain from claiming and restructuring them and locking them in our visual and linguistic prisons. This challenges many orthodoxies in the centres of design; but without calling for such a counterhegemonic turn I will remain implicated as a 'foreign devil of imperialism' in a Faustian story that, Thiong'o (1986) writes, African people have long told.

Acknowledgments I thank all inhabitants of Mankosi, especially LRs (Masbulele, Bongiwe, Roico, Nomphello, Senzo, Mvuzo, Nowelthu, Thumeka, Azola, and Khululwa), my neighbours and friends (Kholeka, Sibongile, Lusy, Nellie, Thatiswa, Maddy, Andre, Pedro, Domi, Roger, Judy, Nelsie, Carlos, Prune and Cody): Ndiyabulela kakhulu ngempatho endenze ndaziva ndikhuselekile kwilali yenu nangokundifundisa ukunimamela. I am grateful to Gary Marsden for the Charging Stations, his friendship and his vision that is lived in Thomas Reitmaier, who designed and developed Audio Repository and Our Voices and engaged willingly with African orality. I thank Simon Robinson and Matt Jones for tablets and MXShare, Sam Merritt for early ideas about Nguigi wa Thiong'o, Lesley Green for pointing me to Sloterdijk and Alan Chamberlain for alerting me to Irobi. I am grateful to Mounia Lalmas, Paula Kotze and Bill Tucker for their support, and Marion Watson, truna, Lilly Irani, Paul Dourish, Lisa Nathan and Satinder Gil for their confidence in me. Finally, I thank the reviewers of this article for their provocation and guidance. Our work was funded mostly by CSIR-Meraka, South Africa and partially by EPSRC Grant (EP/H042857/1).

\section{References}

Adichie CM (2006) Our 'Africa' Lenses. washingtonpost.com. Monday, November 13, 2006
Achebe C, Brooks J (1994) The Art of Fiction No. 139: Interview of Chinua Achebe by Jerome Brooks The Paris Review. www. theparisreview.org/interviews/1720/the-art-of-fiction-no-139chinua-achebe

Berber K (2005) Text and performance in Africa. Oral Tradition 20(2):264-277

Best ML, Smyth TN, Serrano-Baquero D, Etherton J (2009) Designing for and with diaspora: a case study of work for the truth and reconciliation commission of Liberia. In Proc. CHI 2009. 2903-2918. ACM Press

Best M, Smyth TN, Etherton J, Wornyo E (2010) Uses of mobile phones in post-conflict liberia. Inf Tech Int Dev 6(2):91-108

Best ML, Long WJ, Etherton J, Smyth T (2011) Rich digital media as a tool in post-conflict truth and reconciliation. Media War Conflict 4(3):231-249

Bhagwat P, Raman B, Sanghi D (2004) Turning 802.11 insideout. SIG- COMM Comput Commun Rev, 34(1) 33-38. ACM Press

Bidwell NJ (2009) Anchoring design to rural ways of doing and saying. In Proc. INTERACT'09: the International Conference on Human-Computer Interaction. Lecture Notes in Computer Science, (5726): 686-699

Bidwell NJ (2010) Ubuntu in the network: humanness in social capital in rural South Africa. Interactions 17(2):68-71

Bidwell NJ, Siya MJ (2013) Situating asynchronous voice in rural Africa.In: Proc. INTERACT 2013. Springer, 36-53

Bidwell NJ, Winschiers-Theophilus H (2012) Audio pacemaker: walking, talking indigenous knowledge. SAICSIT'12. ACM Press. pp 149-58

Bidwell NJ, Reitmaier T, Marsden G, Hansen S (2010) Designing with mobile digital storytelling in rural Africa. In: Proc. CHI' 10. ACM 1593-1602

Bidwell NJ, Winschiers-Theophilus H, Koch-Kapuire G, ChivunoKuria S (2011a) Situated interactions between audiovisual media and African herbal lore. Pers Ubiquit Comput 15(6):609-627

Bidwell NJ, Lalmas M, Marsden G, Dlutu B et al (2011b) Please call ME.N.U.4EVER: designing for 'callback' in rural Africa. Proc. IWIPS'11 117-138

Bidwell NJ, Reitmaier T, Rey-Moreno C et al (2013a) Timely Relations in Rural Africa. In: 12th Int'l Conf. on Social implications of computers in developing countries IFIP

Bidwell NJ, Siya MJ, Marsden G et al (2013b) Walking the Social Life of Solar Charging. ACM Trans Comput Human Interact 20(4): $1-33$

Bidwell NJ, Reitmaier T, Jampo K (2014a) Orality, gender and social audio in rural Africa. In: Proc. 11th Int'l conference on the design of cooperative systems. Springer. 225-241

Bidwell NJ, Robinson S, Vartiainen E et al (2014b) Designing socialmedia for community information sharing in rural South Africa. In: Proc. SAICSIT2014. ACM Press

Burrell J (2010) Evaluating shared access: social equality and the circulation of mobile phones in rural uganda. J Comput Mediat Commun 15:230-250

Castells M (2004) Afterword: why networks matter. Network Logic. DEMOS, 2004

Chigona W, Chigona A, Ngqokelela B, Mpofu S (2009) MXit: uses, perceptions and self-justifications. JIITO 4:1-16

Cleaver, F (2001) Institutions, Agency and the limitations of participatory approaches to development. In: Participation the New Tyranny. Ed Bill Cook \& Uma Kothari, Zed Books. pp 36-55

Coetzee JM (2013) On Nelson Mandela (1918-2013). Retrieved Feb 2014 from: www.nybooks.com/articles/archives/2014/jan/09/ nelson-mandela-1918-2013/

Cook B, Kothari U (2001) Participation the New Tyranny. Zed Books. pp 36-55 
Dodson L, Sterling L, Bennett J (2013) Minding the gaps: cultural, technical and gender-based barriers to mobile use in orallanguage berber communities. Proc. ICTD'13. ACM. pp 79-88

Finnegan R (2007) The oral and beyond: doing things with words in Africa. James Curry/Uni. of Chicago Pr

Friedman B, Hendry DG (2012) The envisioning cards: a toolkit for catalyzing humanistic and technical imaginations. Proc. CHI'12, ACM

Frohlich D, Rachovides D, Riga K, Bhat R, Frank M, Edirisinghe E, Wickramanayaka D, Jones M, Harwood W (2009) StoryBank: mobile digital storytelling in a development context. In Proc. CHI '09, ACM. pp 1761-1770

Frohlich D, Robinson S, Eglinton K, Jones M, Vartiainen E (2012) Creative cameraphone use in rural developing regions. In: Proc. MobileHCI. ACM Press

Gill SP (2012) Rhythmic synchrony and mediated interaction: towards a framework of rhythm in embodied interaction. AI \& SOCIETY 27, 1, pp 111-127

Gorman T, Rose E, Yaaqoubi J et al (2011) Adapting usability testing for oral, rural users. In: Proc. CHI'11, ACM Pr. pp 1437-1440

Gyekye K (1987) An essay on African philosophical thought: the Akan conceptual scheme. Cambridge University Press, Cambridge

Hallen B (2009) A short history of African philosophy (2nd Edn)

Harrell FD (2007) Cultural roots for computing: the case of african diasporic orature and computational narrative in the GRIOT system.In: Proc. DAC'07

Henkel H, Stirrat R (2001) Participation as spiritual duty, empowerment as secular subjection. In: Participation the New Tyranny. Ed Bill Cook \& Uma Kothari, Zed Books. pp 168-184

Hull G, Schultz K (2001) Literacy and learning out of school: a review of theory and research. Rev Edu Res 71(4):575-611

Hutchins EL, Hollan JD, Norman DA (1985) Direct manipulation interfaces. Human Comput Interact 1(4):311-338

Ikuenobe P (2006) Philosophical perspectives on communalism and morality in African traditions. Lexington Books

Ingold T (2007) Lines: a brief history. Routledge

Irani L, Vertesi IJ, Dourish P, Philip K, Grinter RE (2010) Postcolonial computing: a lens on design and development. In Proc. CHI'10 ACM. pp 1311-1320

Irobi E (2008) The problem with post-colonial theory: re-theorizing African performance, orature and literature in the age of globalization and diaspora studies. Sentinel Lit Q 2:1

Jousse M (2000) The anthropology of geste and rhythm. In: E. Sienaert (eds) Translated in collaboration with J. Conolly. Cape Town: Mantis

Kaschula R (2002) The bones of the ancestors are shaking: xhosa oral poetry in context. Juta, Cape Town

Kaschula RH (2004) Imbongi to slam: the emergence of a technologised auriture. South Afr J Folk Stud 14(2):45-58

Klemmer SR, Hartmann B, Takayama L (2006) How bodies matter: five themes for interaction design. In: Proc. CHI'06, ACM, pp 140-149

Kreitmayer S, Laney R, Peake S, Rogers R (2013) Sharing bubbles: reflections on offline multi-surface scenarios. UbiComp '13

Ladeira I, Cutrell E (2010) Teaching with storytelling: an investigation of narrative videos for skills training. In Proceedings of ICTD 2010, the 4th ACM/IEEE

Lopisteguy P, Dagorret, Latapy M (2006) Interactive applications for communicational situations: assets of genre and verbal interactions. In: Proceedings of SIGDOC'06, ACM. pp 202-209

Maunder A, Marsden G, Harper R (2008) SnapAndGrab - Accessing and sharing contextual multi-media content using Bluetooth enabled cameraphones and large situated displays. In: Proceedings CHI 2008. ACM Press, Florence, Italy, pp 2319-2323

Mbiti JS (1990) African religions and philosophy. Heinemann, Harlow
Medhi I, Sagar A, Toyama K, Text-Free 1 (2007) User Interfaces for Illiterate and Semiliterate Users. Information Technologies \& Int'l Development 4, 37-50

Medhi I, Menon RS, Cutrell E, Toyama K (2012) Correlation between limited education and transfer of learning. Inf Technol Int Dev $8(2): 51-65$

Merritt S, Bardzell S (2011) Postcolonial language and culture theory for HCI4D. Ext. Abstracts CHI'11 ACM. pp 1675-1680

Mkabela Q (2005) Using the Afro centric method in researching indigenous African culture. Qual Rep 10(1):178-189

Moolla FF (2012) When orature becomes literature: somali oral poetry and folktales in Somali novels. Comparative Literature Studies 49(3):434-462

Mosse D (2001) People's knowledge', participation and patronage: operations and representations in rural development. In: Participation the New Tyranny. Ed. Bill Cook \& Uma Kothari, Zed Books pp 36-55

Mudliar P, Donner J, Thies W (2012) Emergent practices around CGNet Swara, voice forum for citizen journalism in rural India. In: Proc. ICTD '12. ACM press. pp 159-68

Ndwe T, Barnard E, Mqhele E, Dlodlo E (2012) Effects of application type on the choice of interaction modality in IVR systems. In: Proc. SAICSIT'12, ACM press. pp 236-242

Ntibagirirwa S (2001) a wrong way: from being to having In. The African value system. In: protest and engagement: philosophy after apartheid at an historically black South African University. Edited: Patrick Giddy. The council for research in values and philosophy. pp 65-81

Oduor EN, Neustaedter K, Judge TK et al (2014) How Technology Supports Family Communication in Rural, Suburban, and Urban Kenya. Proc. CHI'14

Okephwo I (1992) African oral literature. Indiana University Press, Indianapolis

Ong J (1982) Orality and literacy: the technologizing of the word. Routledge Press, New York

Oyewumi O (1997) The invention of women making an African sense of western gender discourses. U. of Minnesota Press

Oyewumi O (2010) Gender epistemologies in Africa: gendering traditions, spaces, social institutions, and identities. Palgrave Macmillan

Patel N, Chittamuru D, Jain A, Paresh D, et al (2010) Avaaj Otalo: a field study of an interactive voice forum for small farmers in rural India. In: Proc. CHI'10, ACM 733-42

Peters AN, Oren MA, Bidwell NJ (2012) Self-representation and friendship connections of Namibians on Facebook. 12th annual grace hopper celebration of women in computing, Oct. 3-6, Baltimore

Pitula K, Dysart-Gale D, Radhakrishnan TA (2010) Case study in requirements engineering for ICT4D. Inform Technol Int'l Dev 6(1):78-93

Pritchard GW, Vines J (2013) Digital apartheid: an ethnographic account of racialised HCI in Cape Town Hip-Hop. In: Proc. CHI 2013

Reitmaier T (2012) "She looked deep into our eyes": reflections on cross-cultural practice in rural Africa. Knowl Manag Dev J 7(3):327-339

Reitmaier T, Bidwell NJ, Marsden G (2011) Situating digital storytelling within African communities. Int J Human Comput Stud 69(2011):283-286

Reitmaier T, Bidwell NJ, Siya M, et al (2012) Communicating in designing an oral repository for rural African villages. In: Proc. IST-Africa

Rodil K, Rehm M, Winschiers-Theophulus H (2013) Homestead creator: using card sorting in search for culture-aware categorizations of interface objects. In: Proc. INTERACT'13, Springer. pp 437-444 
Scribner S, Cole M (1981) The psychology of literacy. Harvard Univ. Pr, Cambridge

Sherwani J, Ali N, Rosé CP, Rosenfeld R (2009) Orality-grounded HCID: understanding the Oral User. Inform Technol Int'l Dev 5(4):37-50

Sloterdijk P (2011) Bubbles: spheres volume I: Microspherology, translation by Wieland Hoban, Cambridge, MIT Press, 2011

Smyth TN, Etherton J, Best ML (2010) MOSES: exploring new ground in media and post-conflict reconciliation. In Proc. CHI 2010. ACM Press (2010), pp 1059-1068

Sullivan B (2012) Freedom to learn: blending interactive voice response and radio. In: Learning with community media, (2012), chap. 21, 131-135

Tacchi J, Slater D, Lewis P (2003) Evaluating community based media initiatives: an ethnographic action research approach. In: Proc. IT4D, 2003

Taylor A (2011) Out there. In Proc.of the SIGCHI conference on human factors in computing systems. pp 685-694

Thiong'o, N (1965) The river between. Heinemann, Publishers

Thiong'o N (1986) Decolonising the mind: the politics of language in African literature. East African Publishers, James Currey Ltd/ Heinemann

Thiong'o N (1993) Moving the centre: the struggle for cultural freedoms. James Currey, London

Thiong'o N (2009) Something torn and new: an African renaissance. Basic Books

Thiong'o N (2009) The myth of the tribe in African politics. Transition 1010. JSTOR Issue 101

Thiong'o N (2013) In the house of the interpreter: a memoir. Vintage
Truax B (2001) Acoustic communication. Greenwood Press, Westport

Tucker W, Blake E (2008) The role of outcome mapping in developing a rural telemedicine system. In Proc. IST-Africa'08, eds. Cunningham, P. \& Cunningham, M. IIMC Int. Information Management Corp

Turner NS (2007) The mnemonic oral tradition with special reference to the management and expression of conflict in Zulu-speaking communities. Literator 28(2):75-99

Verran H (2001) Science and an African logic. The University of Chicago Press, Chicago

Walton M, Haßreiter S, Marsden G, Allen S (2012) Degrees of sharing: proximate media sharing and messaging by young people in Khayelitsha. Proc. MobileHCI'12, ACM. pp 403-412

Winschiers-Theophilus H, Bidwell NJ (2013) Toward an afro-centric indigenous hci paradigm. Int $\mathrm{J}$ Human Comput Interect 29(4):243-255

Winschiers-Theophilus H, Bidwell NJ, Blake E, Koch Kapuire G (2012) Community consensus: design beyond participation. Design Issues 28(3):89-100

Wiredu K, Gyekye K (1992) Person and community: Ghanaian philosophical studies. Council for research in values and philosophy

Wyche SP, Schoenebeck SY, Forte A (2013) "Facebook is a luxury": an exploratory study of social media use in rural Kenya. In: Proceedings of ACM Conference on Computer Supported Cooperative Work and Social Computing (CSCW'13). San Antonio, TX 